\title{
Ambroxol for the treatment of fibromyalgia: science or fiction?
}

\section{Kai-Uwe Kern \\ Myriam Schwickert}

Institute of Pain Medicine/Pain Practice, Wiesbaden, Germany

Correspondence: Kai-Uwe Kern Institute of Pain Medicine/Pain Practice, 68 Sonnenberger Strasse, Wiesbaden 65193, Germany

$\mathrm{Tel}+4961 I 20592636$

Fax +49 6II 16877838

Email dr.kern@schmerzpraxiswiesbaden.de
This article was published in the following Dove Press journal:

Journal of Pain Research

16 August 2017

Number of times this article has been viewed

\begin{abstract}
Fibromyalgia appears to present in subgroups with regard to biological pain induction, with primarily inflammatory, neuropathic/neurodegenerative, sympathetic, oxidative, nitrosative, or muscular factors and/or central sensitization. Recent research has also discussed glial activation or interrupted dopaminergic neurotransmission, as well as increased skin mast cells and mitochondrial dysfunction. Therapy is difficult, and the treatment options used so far mostly just have the potential to address only one of these aspects. As ambroxol addresses all of them in a single substance and furthermore also reduces visceral hypersensitivity, in fibromyalgia existing as irritable bowel syndrome or chronic bladder pain, it should be systematically investigated for this purpose. Encouraged by first clinical observations of two working groups using topical or oral ambroxol for fibromyalgia treatments, the present paper outlines the scientific argument for this approach by looking at each of the aforementioned aspects of this complex disease and summarizes putative modes of action of ambroxol. Nevertheless, at this point the evidence basis for ambroxol is not strong enough for clinical recommendation.
\end{abstract}

Keywords: Nav 1.8, Nav 1.7, bromhexine, hyperalgesia, sympathetically maintained pain, central sensitization, interleukins, neuropathic pain, sodium channels

\section{Introduction}

Fibromyalgia syndrome (FMS) is a chronic, undegenerate symptom complex that is characterized by chronic widespread pain and evoked pain at tender points. Other common symptoms include insomnia, depression, fatigue, stiffness, and gastrointestinal disorders. ${ }^{1-3}$ Approximately $2 \%-5.8 \%$ of the population of industrial countries suffer from FMS, ${ }^{1,4-9}$ and $80 \%-90 \%$ of patients are female. Although FMS is classified as a noninflammatory disorder, there is increasing evidence for changes in inflammatory mediators, ${ }^{10-15}$ and a disturbed balance in pro- and anti-inflammatory cytokines is being discussed. ${ }^{12,16-18}$ In addition, it is also considered a stress-related-disorder with dysfunction of the hypothalamic-pituitary-adrenocortical axis. ${ }^{19-21}$ Furthermore, increases in oxidative stress and toxic metabolites of lipid peroxidation have been shown for FMS. ${ }^{22-24}$ It has been proposed that fibromyalgia could be a sympathetically maintained neuropathic pain syndrome. ${ }^{25}$ Moreover, it has been suggested that dorsal root ganglia and peripheral sensory neuron sodium channels may play a major role in fibromyalgia pain transmission. ${ }^{26}$

In previous publications, we described the successful topical treatment of neuropathic pain $^{27,28}$ and nociceptive pain ${ }^{29}$ with ambroxol cream in a case series. Furthermore, not only have we observed beneficial topical and oral individual treatment results in FMS 
(Figures 1-3; Kern KU. Data on file. Personal clinical observations. 2011-2017) but also other investigators have observed similar effects using oral ambroxol, ${ }^{30,31}$ both of which certainly could be regarded as placebo effects at this stage. Ambroxol is a secretolytic substance, but may also potentially influence several pathophysiological mechanisms involved in fibromyalgia. First, ambroxol interferes with oxidative stress and influences cytokines and inflammation. ${ }^{32,33}$ Second, ambroxol blocks sodium channels, ${ }^{34}$ especially the tetrodotoxin-resistant (TTX-r) channel subtype $\mathrm{Na}_{\mathrm{v}} 1.8,{ }^{34-36}$ which is expressed particularly in spinal ganglion cells ${ }^{37}$ and in nociceptive, sensory neurons. ${ }^{37-40}$ This should limit central sensitization in chronic widespread muscle pain, ${ }^{41}$ which clearly also occurs in FMS. ${ }^{42}$ Based on these effects, ambroxol may be an interesting treatment approach for FMS, even if detailed examinations concerning these single mechanisms remain to be performed and an influence of ambroxol on inhibitory descending pain pathways, important in FMS, has not yet been examined. The present paper outlines the scientific argument for the treatment of fibromyalgia using ambroxol by looking at many different aspects of this complex disease and summarizes putative modes of action (Tables 1-3, Figure 4).

\section{Skin, mitochondria, and mast cells Skin condition}

Salemi et $\mathrm{al}^{43}$ detected IL1 $\beta$, IL6, and TNF $\alpha$ in skin biopsies of a subgroup of approximately $30 \%$ of FMS patients, but not in control subjects. This finding was interpreted as the presence of inflammatory foci indicating neurogenic inflammation, which might be the reason for the efficacy of nonsteroidal anti-inflammatory therapy, which has occasionally been reported. IL1 $\beta,{ }^{44,45}$ IL6, ${ }^{44,46,47}$ and TNF $\alpha^{44-46,48-52}$ are inhibited by ambroxol. Blanco et $\mathrm{al}^{53}$ demonstrated an increased number of mast cells in FMS patients, the secretion of which was also inhibited by ambroxol. ${ }^{54-56}$ Other skin biopsies have shown significant mitochondrial dysfunction and an increased level of oxidative metabolites, in conjunction with inflammatory signs ${ }^{57,58}$ correlated with pain. ${ }^{57}$ Ambroxol also improves mitochondrial dysfunction ${ }^{59-61}$ and oxidative stress. ${ }^{44,60,62-65}$ Uçeyler et al ${ }^{66}$ investigated the gene expression of the proinflammatory cytokines TNF $\alpha$, IL6, and IL8 and the anti-inflammatory IL10 in skin biopsies of 25 FMS patients, compared these to patients with depression and healthy controls, and found no detectable differences. The results did not support the hypothesis of these cytokines being involved in the sensitization of peripheral nerves in the skin. In one of the most comprehensive investigations with skin biopsies, FMS patients had reduced intraepidermal nerve-fiber density compared to controls, which supports the view that the pain syndrome in a subgroup of FMS patients is partially of neuropathic origin. ${ }^{67}$ In vitro and in vivo investigations have demonstrated that ambroxol can relieve neuropathic pain. ${ }^{28,29,68-71}$ Our clinical practice observations have shown pain relief in FMS following some oral treatments or topical application of ambroxol $20 \%$

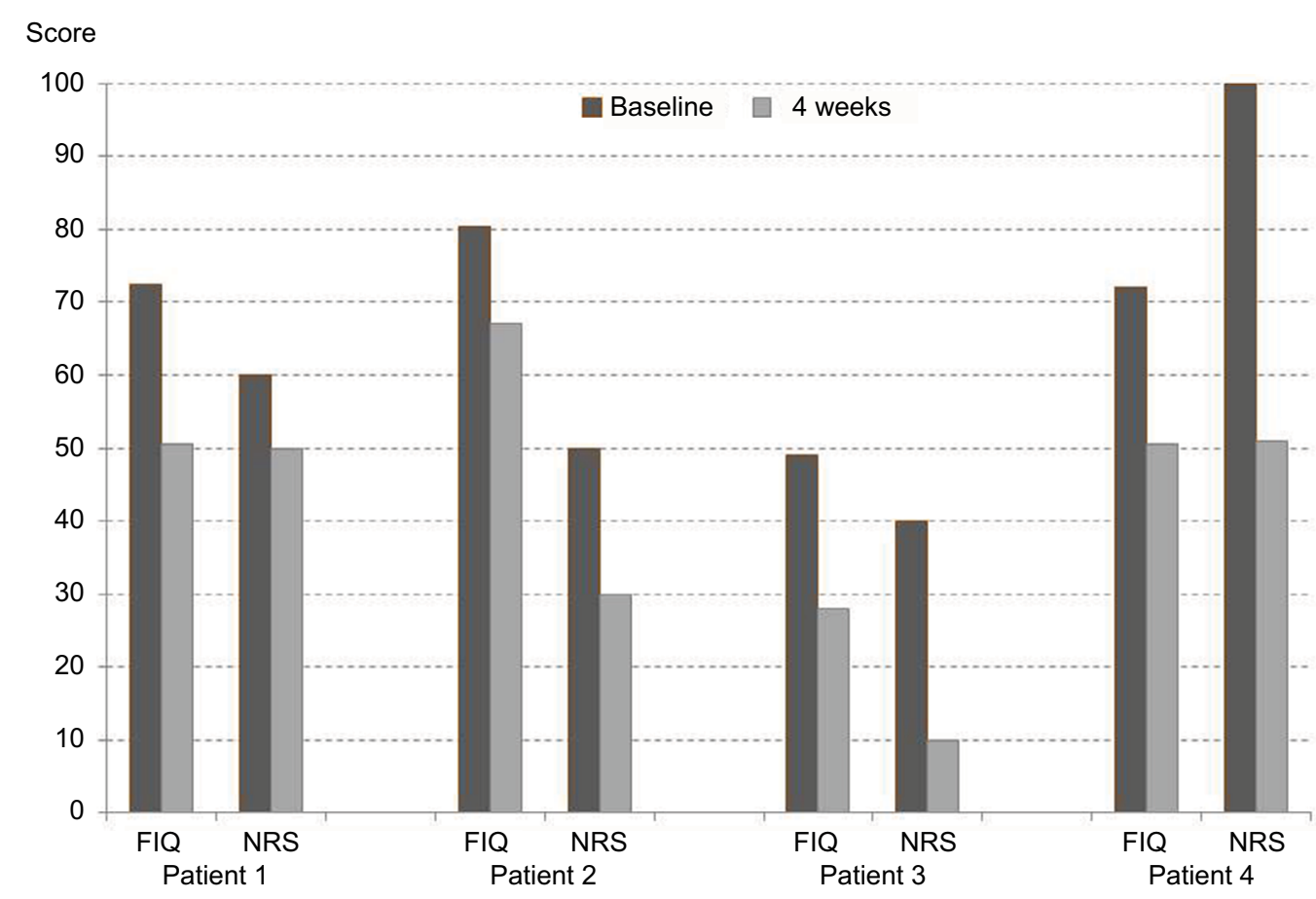

Figure I Individual development of FIQ and NRS in four responders to oral ambroxol for fibromyalgia.

Note: 4 weeks of ambroxol orally, $75 \mathrm{mg}$ retarded. Kern KU, data on file - personal clinical observations, 20II-20I7.

Abbreviations: FIQ, Fibromyalgia Impact Questionnaire; NRS, numeric rating scale (0-100). 


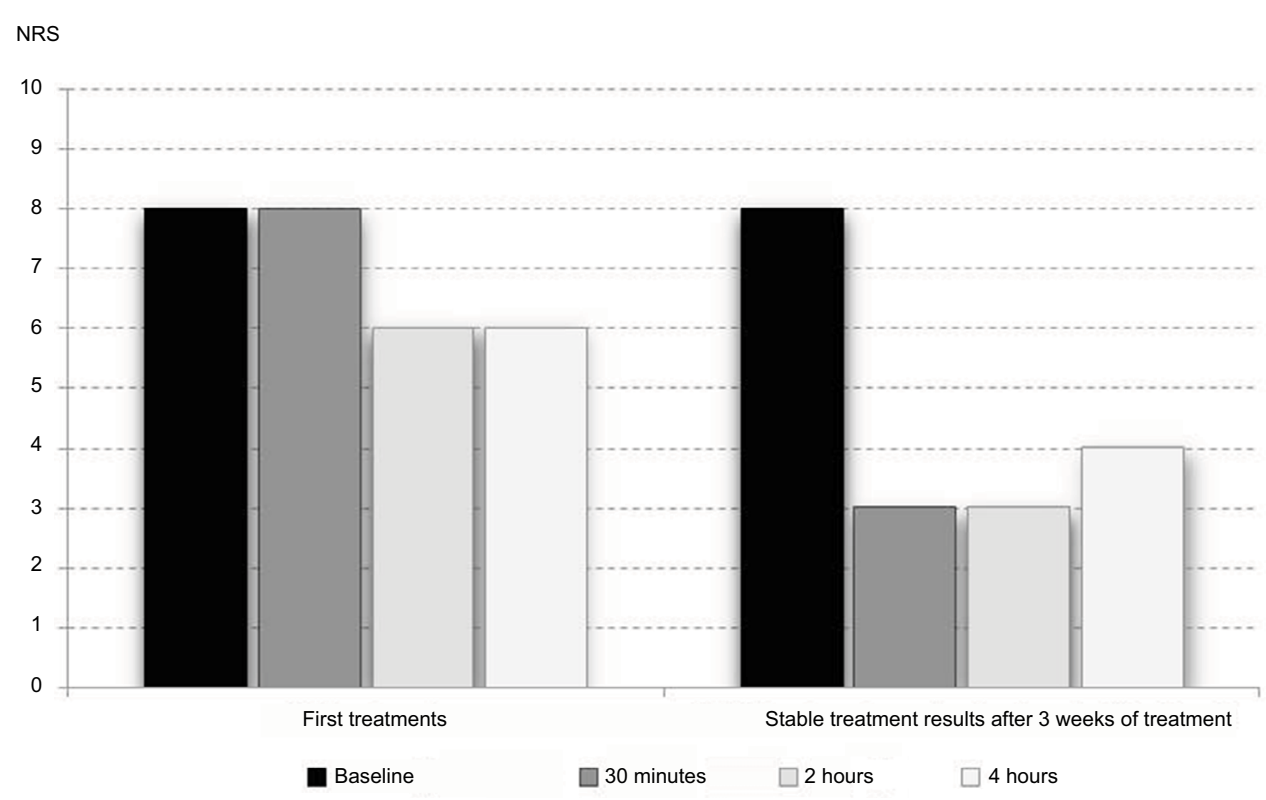

Figure 2 Passage of time of fibromyalgia pain reduction.

Note: Following initial topical ambroxol $20 \%$ treatment (hands and elbows) and results after 3 weeks of treatment in a single patient. Kern KU, data on file - personal clinical observations, 201 I-2017.

Abbreviation: NRS, numeric rating scale (0-10).

NRS

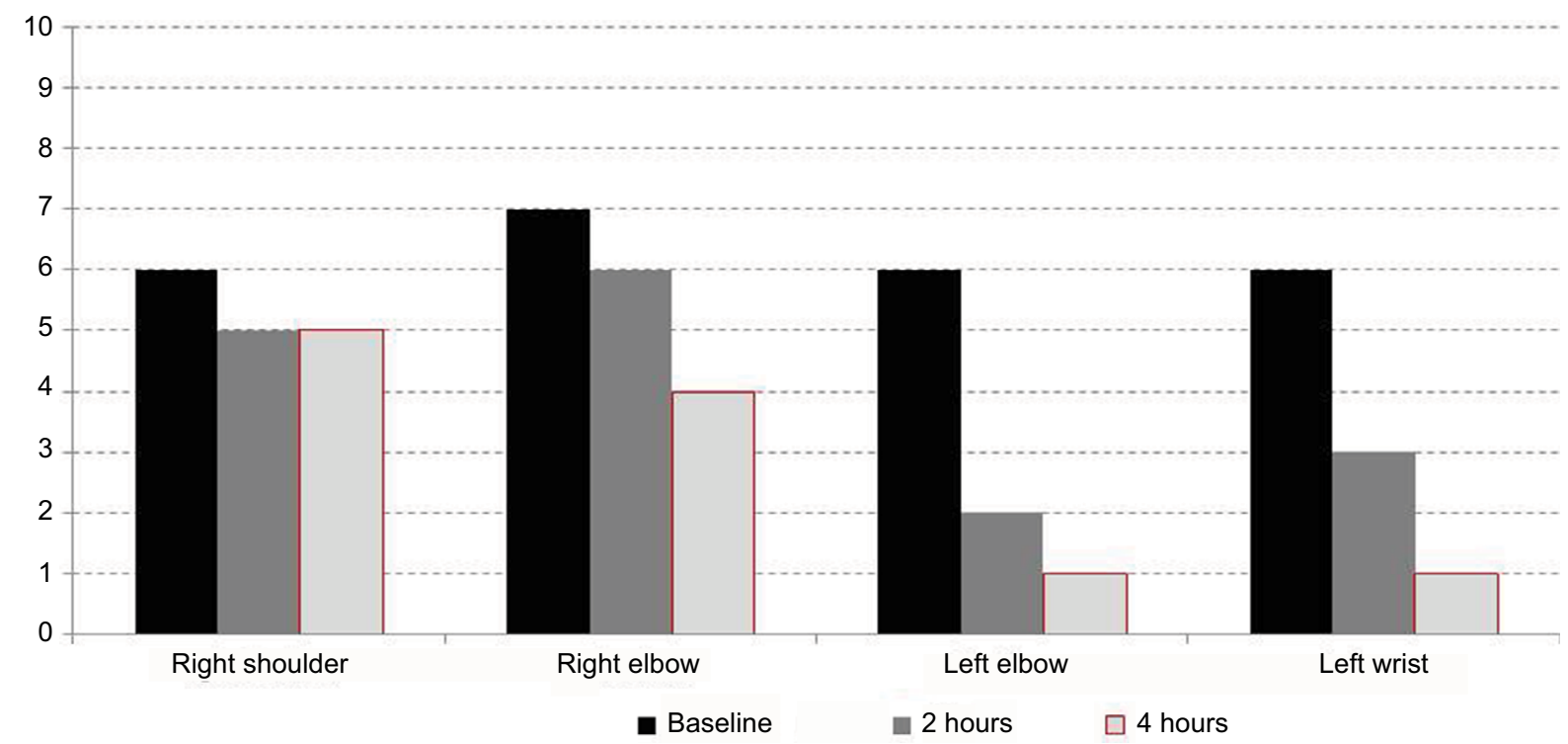

Figure 3 Passage of time of fibromyalgia pain reduction.

Note: Following topical ambroxol $20 \%$ treatment of different pain locations (single treatment in a single patient). Kern KU, data on file - personal clinical observations, 20II-2017.

Abbreviation: NRS, numeric rating scale (0-10).

cream (Figures 1-3; Kern KU. Data on file. Personal clinical observations. 2011-2017), which according to the aforementioned relationships need not necessarily be attributed solely to the local anesthetic properties of the compound, especially when improved over time (Figure 2).

Whole-body cryotherapy, beneficial in a subgroup of FMS patients, ${ }^{72}$ works primarily via impact on the skin. This therapeutic approach stabilizes lysosomal membranes, ${ }^{73}$ among others, and reduces the negative effects of proteins of lysosomal enzymes. Ambroxol has a comparable effect. The compound significantly enhances reduced enzyme activity of the lysosomal glucosylceramidase (in Parkinson's disease), ${ }^{74-76}$ as well as $\alpha$-galactosidase A (in Fabry's disease), $\alpha$-glucosidase (in Pompe's disease) ${ }^{77}$ and $\beta$-glucocerebrosidase (in Gaucher's disease). ${ }^{78,79}$ At least for the aforementioned diseases, ambroxol is thus clearly an enzyme-modifying therapeutic option. 
Table I Reported inflammatory and oxidative changes in fibromyalgia, explaining biological pain induction, and potential helpful modes of action of ambroxol

\begin{tabular}{|c|c|c|}
\hline Mechanism & Fibromyalgia & Ambroxol \\
\hline \multicolumn{3}{|l|}{ Inflammation } \\
\hline Inflammation & Discussed & Anti-inflammatory $y^{32,33,46}$ \\
\hline Edema & Common & $\downarrow^{46,152,326}$ \\
\hline Tissue hypoxia and acidosis & Discussed & $\downarrow^{229}$ \\
\hline \multicolumn{3}{|l|}{ Cytokines } \\
\hline \multirow[t]{3}{*}{ Cytokines } & Important in FMS $12,13,264$ & Multiple effects on cytokines ${ }^{32}$ \\
\hline & Influence on HPA axis ${ }^{269-271}$ & \\
\hline & Mediator of neuropathic pain ${ }^{266-268}$ & \\
\hline \multicolumn{3}{|l|}{ Proinflammatory } \\
\hline ILI $\beta$ & $\uparrow 43,281$ & $\downarrow 44,45$ \\
\hline IL2 & Decreased by therapeutic cryotherapy ${ }^{73}$ & $\downarrow^{49}$ \\
\hline IL6 & $\uparrow 12,14,91,199,200,272$ & $\downarrow 44,46,47,205$ \\
\hline IL8 & $\uparrow 12,199,200,273,274,277$ & $\downarrow 47,96,201-205$ \\
\hline IL8 intrathecally & $\uparrow$ Compared to rheumatoid arthritis 199 & Reduced allodynia ${ }^{71}$ \\
\hline TNF $\alpha$ & $\uparrow 43,9,283,327$ & $\downarrow^{44-46,48-52}$ \\
\hline \multicolumn{3}{|l|}{ Anti-inflammatory } \\
\hline ILIRA & $\uparrow 12,199$ & ILI $\downarrow^{44,45,48,51}$ \\
\hline \multirow[t]{2}{*}{ IL4 } & $\downarrow 18,287$ & $\downarrow^{54}$ \\
\hline & $\uparrow$ Compared to rheumatoid arthritis 199 & \\
\hline \multirow[t]{2}{*}{ ILIO } & $\uparrow 13,276,278,281,282$ & Stabilization ${ }^{203,284}$ \\
\hline & Unchanged ${ }^{12,276}$ & \\
\hline \multicolumn{3}{|l|}{ Others } \\
\hline ILI3 & $\downarrow^{287}$ & $\downarrow^{54,285}$ (but helpful as anti-inflammatory) \\
\hline IL5 & $\downarrow \downarrow^{287}$ & $\downarrow^{54,285}$ (but helpful as anti-inflammatory) \\
\hline Cellular immunity & $\downarrow$ ل' & $\uparrow_{86,87,285}\left(\mathrm{Na}_{\mathrm{v}} \mathrm{I} .8 \text { immunomodulatory }\right)^{295}$ \\
\hline NLRP3 inflammasome & Activated 291,292 & $\downarrow$ (free-radical scavengers) $^{44,60,62-65}$ \\
\hline Mast cells & $\uparrow_{53,88}$ & $\downarrow^{54-56}$ (secretions) \\
\hline \multirow[t]{2}{*}{ MCPI } & $\uparrow 150,274,289$ & $\downarrow^{51,95,152}$ \\
\hline & $\begin{array}{l}\text { Correlation/pain intensity }{ }^{150} \\
\uparrow \text { in mutation subpopulation }{ }^{289}\end{array}$ & \\
\hline \multicolumn{3}{|l|}{ Oxidative stress } \\
\hline Oxidative stress & $\uparrow 57,84,115$ & $\downarrow^{\downarrow 45,74,96,104,285}$ \\
\hline Oxidative metabolites & $\uparrow$ (multiple, see below) & $\downarrow 44,59,62,64,65,96,123$ \\
\hline Lipid peroxidation & $\uparrow_{23,81}^{2}$ & $\downarrow^{59,98,99}$ (inhibition) \\
\hline \multicolumn{3}{|l|}{ Oxidative parameters } \\
\hline Superoxide & $\uparrow_{83}$ & $\downarrow^{328}$ \\
\hline Malondialdehyde & $\uparrow_{22-24}^{2}$ & $\downarrow \downarrow^{59,98,99}$ \\
\hline Xanthine oxidase & 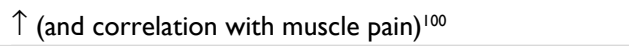 & $\downarrow^{45}$ \\
\hline \multicolumn{3}{|l|}{ Antioxidative parameters } \\
\hline Catalase & $\downarrow^{80,81}$ & $\uparrow 62,101$ \\
\hline Glutathione peroxidase & $\downarrow^{80,81}$ & $\uparrow_{45}$ \\
\hline Superoxide dismutase & $\downarrow^{23,24,80}$ & $\uparrow 45,98,101-104$ \\
\hline \multicolumn{3}{|l|}{ Antioxidative therapies } \\
\hline \multirow[t]{3}{*}{ Melatonin } & New therapeutic strategy ${ }^{|12,| 13}$ & Future strategy? \\
\hline & Potent antioxidant ${ }^{1 / 4}$ & Also antioxidant ${ }^{44,59,62,64,65,96,123}$ \\
\hline & Lipid peroxidation $\downarrow^{110}$ & Lipid peroxidation $\downarrow^{59,98,99}$ \\
\hline Free-radical scavengers & Therapeutic option?100 & Acts as s4,60,62-65 $^{4}$ \\
\hline \multicolumn{3}{|l|}{ Nitrosative stress } \\
\hline Nitrosative stress & $\uparrow 84,115$ & $\downarrow 96$ \\
\hline \multirow[t]{5}{*}{ Nitric oxide } & Correlates with FIQ score ${ }^{119}$ & $\downarrow$ (activity and production) $)^{44,121-123}$ \\
\hline & Involved in pathophysiology?97,116 & \\
\hline & Responsible for pain sensitivity ${ }^{117}$ & \\
\hline & Correlation with pain intensity 18 & \\
\hline & Nitric oxide synthase inhibitors needed for therapy ${ }^{120}$ & \\
\hline
\end{tabular}

Abbreviations: FIQ, Fibromyalgia Impact Questionnaire; FMS, fibromyalgia syndrome; HPA, hypothalamic-pituitary-adrenocortical; $\mathrm{Na}_{\mathrm{v}}$, voltage-gated sodium. 
Reduction of many enzymes is also present in FMS. ${ }^{23,24,80-82}$ Low activity of the enzyme prolyl endopeptidase in serum is even supposed to have predictive diagnostic value. ${ }^{82}$ The possibility of enhancement of this specific enzyme activity by ambroxol should thus be investigated.

\section{Mitochondria}

Mitochondrial dysfunction in FMS has been demonstrated in skin biopsies, ${ }^{57,58}$ blood, ${ }^{83}$ and muscle cells, and may explain muscular pain. ${ }^{84}$ If such mitochondrial dysfunction also occurs in neurons of the central nervous system (CNS),

Table 2 Reported nociceptive and CNS changes, cellular dysfunction, and accompanying symptoms in fibromyalgia

\begin{tabular}{|c|c|c|}
\hline Nociception and CNS & Fibromyalgia & Ambroxol \\
\hline \multirow[t]{8}{*}{ Muscle pain } & Common (multiple) & $\mathrm{Na}_{\mathrm{v}} \mathrm{I} .8$ in $86 \%$ of sensory muscle fibers ${ }^{329}$ \\
\hline & Central sensitization ${ }^{133-135}$ and long-lasting TTX-r & Blockade of involved $\mathrm{Na}_{\mathrm{v}} \mathrm{I} .8$ \\
\hline & activation $^{136}$ & Antioxidative in acidosis $\stackrel{v}{45,74,96,104,285}$ \\
\hline & Tissue acidosis crucial ${ }^{\mid 41,142}$ & Blockade of involved $\mathrm{Na}_{v} \mathrm{I} .8$ \\
\hline & ASIC3 essential ${ }^{139,146} \rightarrow \mathrm{Na}_{v} \mathrm{I} .8$ activity $\uparrow$ & MCPI $\downarrow^{51,95,152}$ \\
\hline & Induction and sensitization by MCPI I50,151 & Xanthine oxidase $\downarrow^{45}$ \\
\hline & Correlation with xanthine oxidase ${ }^{100}$ & $\downarrow$ (or improved) $)^{59-61}$ \\
\hline & $\begin{array}{l}\text { Mitochondrial dysfunction in FMS muscles shown } \\
\text { and "explanation" } 84\end{array}$ & \\
\hline \multirow[t]{4}{*}{ Central sensitization } & Involved in $\mathrm{FMS}^{42,175,176}$ and chronic muscle & $\downarrow$ (via $\mathrm{Na}_{\mathrm{v}} \mathrm{I} .8$ blockade and reduced inflammation) \\
\hline & pain $^{133-136,177}$ & $\mathrm{Na}_{v} \mathrm{I} .8$ blockade helpful or preventive ${ }^{41,92,178}$ \\
\hline & Chronic widespread pain in FMS animal model & \\
\hline & $\mathrm{Na}_{v}$ I.8-associated ${ }^{41}$ & \\
\hline \multirow[t]{2}{*}{ NP } & Involved ${ }^{153-156}$ & $\downarrow^{27-29,34,69-71,165,330}$ \\
\hline & Cytokines as mediators ${ }^{266-268}$ & Multiple effects on cytokines ${ }^{32}$ \\
\hline Allodynia/hyperalgesia & Common ${ }^{156,180-182}$ & $\downarrow 68,69,71$ \\
\hline Heat hyperalgesia & Reported ${ }^{156}$ & Suppressed by $100 \%{ }^{69}$ \\
\hline Cold hyperalgesia & Reported ${ }^{173,185,186}$ & Reduced by approximately $75 \%{ }^{69}$ \\
\hline \multirow[t]{2}{*}{ Mechanical allodynia } & Reported ${ }^{156}$ & Reduced by approximately $75 \% 69$ \\
\hline & & Reduced in monoarthritis pain by $50 \%{ }^{69}$ \\
\hline \multirow[t]{2}{*}{ Neurodegeneration } & TPeripherally ${ }^{42,154,162,163}$ & $\downarrow^{192,225,229}$ \\
\hline & $\uparrow$ Also in CNS (eye) $)^{162,163}$ & $\downarrow$ (improves CNS regeneration) ${ }^{225}$ \\
\hline \multirow[t]{3}{*}{ Small-fiber pathology } & Reported $67,159,160,162-164$ & Mainly nociceptive $\mathrm{C}$-fibers with expressed $\mathrm{Na}_{v}$ \\
\hline & & $1.8^{37-40,166-168}$ and thus blocked \\
\hline & & NP $\downarrow^{27-29,34,69-71,165,330}$ \\
\hline \multirow[t]{2}{*}{ SNS } & Involved ${ }^{193-196}$ & $\mathrm{Na}_{\mathrm{v}} \mathrm{I} .8$ blockade also on $\mathrm{SNS} \mathrm{S}^{197,198}$ \\
\hline & & IL8 $\downarrow^{96,201-205}$ and so sympathetically maintained pain \\
\hline \multirow[t]{3}{*}{ Glia } & Activation important $\mathrm{t}^{17,200,212-214}$ & Activation $\downarrow$ : IL8 $\downarrow^{96,201-205}$ and $\alpha$-synuclein $\downarrow^{224}$ \\
\hline & Activation increases IL $8^{207}$ & \\
\hline & IL $8^{206}$ and $\alpha$-synuclein increase activation ${ }^{219}$ & \\
\hline \multirow[t]{3}{*}{ Dopamine } & $\uparrow^{221}$ & $\alpha$-synuclein $\downarrow^{224}$ \\
\hline & Dysfunction 221,222 & $\rightarrow$ dopaminergic neurodegeneration $\downarrow$ \\
\hline & Impaired neurotransmission ${ }^{223}$ & \\
\hline \multicolumn{3}{|l|}{ Dysfunction } \\
\hline \multirow[t]{2}{*}{ Mitochondrial dysfunction } & $\uparrow\left(\text { skin, }^{57,58} \text { blood, }^{57,58,83-85} \text { muscle }\right)^{84}$ & $\downarrow$ or improved ${ }^{59-61}$ \\
\hline & Improvement is therapeutic option ${ }^{85}$ & \\
\hline Lysosomal dysfunction & Whole-body cryotherapy helpful ${ }^{72,73}$ & $\downarrow^{331}$ \\
\hline \multirow[t]{2}{*}{ Enzymes } & $\downarrow 23,24,80-82$ & $\uparrow(\text { multiple) })^{74-79}$ \\
\hline & Prolyl endopeptidase reduction predictive ${ }^{82}$ & \\
\hline Cellular immunity & $\downarrow ' 1$ & $\uparrow 86,87$ \\
\hline IFN $\gamma$ (immunostimulatory) & $\uparrow_{332}$ & $\downarrow 49,50,284$ \\
\hline Cortisone receptor & $\downarrow^{94}$ & Similar efficacy, but independent ${ }^{46,51,95,96}$ \\
\hline \multicolumn{3}{|l|}{ Accompanying symptoms } \\
\hline Overactive bladder & Common, ${ }^{296}$ often painful ${ }^{298}$ & Inhibition of overactivity ${ }^{299}$ \\
\hline \multirow[t]{2}{*}{ Irritable bowel syndrome } & Common $^{300,301}$ & $\mathrm{Na}_{v}$ I.8 blockade reduces colon hyperalgesia ${ }^{307}$ \\
\hline & & Dysfunction ${ }^{234}$ and visceral pain ${ }^{308,309}$ \\
\hline \multirow[t]{2}{*}{ Dry eyes } & $\uparrow$ in FMS and FMS $\uparrow$ in Sjögren's syndrome ${ }^{311-313}$ & Increases tear secretion ${ }^{314}$ \\
\hline & & Improves sicca symptoms ${ }^{315}$ \\
\hline
\end{tabular}


Table 2 (Continued)

\begin{tabular}{|c|c|c|}
\hline Ambroxol treatment & & \\
\hline Ambroxol dosage used & $\begin{array}{l}\text { First individual FMS treatments: } \\
\text { - } 3 \times 30 \mathrm{mg} \text { orally }{ }^{30} \\
\text { - } 75 \mathrm{mg} \text { retarded (Kern KU. Data on file. } \\
\text { Personal clinical observations. 20I I-20I7) } \\
\text { - } 20 \% \text { cream topically (Kern KU. Data on file. } \\
\text { Personal clinical observations. 20I I -20I7) }\end{array}$ & $\begin{array}{l}\text { Prenatal lung maturation: I g IV } \mathrm{IV}^{316} \\
\text { ARDS (children }<\text { I year): up to } 40 \mathrm{mg} / \mathrm{kg} / \mathrm{day}^{322} \\
\text { Atelectasis: I g IV } 317 \\
\text { Gaucher's: I,300 mg/day }{ }^{79} \\
\text { Parkinson's: I,050 } \mathrm{mg} / \text { day }^{76} \\
\text { Individual reports (safe): } \\
\text { - up to } 3 \mathrm{~g} / \text { day over } 53 \text { days }^{318-320} \\
\text { - oral } 1.3 \mathrm{~g} / \text { day over } 33 \text { days }^{321}\end{array}$ \\
\hline Treatment durations & First individual FMS treatments: $4-6$ weeks & $\begin{array}{l}\text { Clinically used treatment durations: } \\
90 \mathrm{mg} \text { for } 3 \text { months } \mathrm{s}^{52} \\
2 \times 75 \mathrm{mg} \text { for } 6 \text { months } \mathrm{s}^{324} \text { and I year } 325 \\
\text { Ongoing trial: } 225-1,050 \mathrm{mg} / \text { day for } 52 \text { weeks }^{76}\end{array}$ \\
\hline
\end{tabular}

Note: Potentially helpful modes of action of ambroxol and reported dosage and treatment durations included.

Abbreviations: ARDS, acute respiratory distress syndrome; ASIC, acid-sensing ion channel; CNS, central nervous system; FMS, fibromyalgia syndrome; IV, intravenous; $\mathrm{Na}_{v}$, voltage-gated sodium; NP, neuropathic pain; SNS, sympathetic nervous system; TTX-r, tetrodotoxin-resistant.

Table 3 Relevance of sodium channels and corresponding therapeutic approaches

\begin{tabular}{|c|c|c|}
\hline Sodium channels & Fibromyalgia & Ambroxol \\
\hline Sodium channels & Important ${ }^{26,196,333}$ & Sodium-channel blockade ${ }^{34-36}$ \\
\hline $\mathrm{Na}_{\mathrm{v}} \mathrm{I} .7$ & Polymorphism found in severe $\mathrm{FMS},{ }^{26}$ important in DRGs ${ }^{196}$ & $\mathrm{Na}_{\mathrm{v}} \mathrm{I} .7$ blockade ${ }^{107,259}$ \\
\hline \multirow[t]{4}{*}{$\mathrm{Na}_{\mathrm{v}} \mathrm{I} .8$} & Expressed in (damaged) small C-fibers ${ }^{37-40,166-168,171}$ & $\mathrm{Na}_{\mathrm{v}} \mathrm{I} .8$ blockade $^{34,35}$ \\
\hline & Important for sensitization ${ }^{171,190,304,334,335}$ & \\
\hline & Important for cold pain ${ }^{38,174}$ (as in FMS) ${ }^{173}$ & \\
\hline & Gain-of-function mutations: FMS-like symptoms ${ }^{170,171,230,234,236}$ & \\
\hline \multirow[t]{2}{*}{ Lidocaine (unspecific blockade) } & Helpful ${ }^{129-132,336}$ & 40 -fold more potent ${ }^{36}$ \\
\hline & Not helpfu| $\left.\right|^{337,338}$ & |2-fold more specific for $\mathrm{Na}_{v} \mid .8^{36}$ \\
\hline \multicolumn{3}{|l|}{$\mathrm{Na}_{v} \mathrm{I} .7$ and $\mathrm{Na}_{v} \mathrm{I} .8$ blocker } \\
\hline \multirow[t]{2}{*}{ Duloxetine } & Helpful ${ }^{157,238}$ & $\mathrm{Na}_{\mathrm{v}} \mathrm{I} .7$ blockade $\mathrm{b}^{107,259}$ \\
\hline & Impact: blockade of $\mathrm{Na}_{\mathrm{v}} \mathrm{I} .7$ and $\mathrm{Na}_{\mathrm{v}}$ I. $8^{240,241}$ & $\mathrm{Na}_{\mathrm{v}} \mathrm{I} .8$ blockade $^{34,35}$ \\
\hline \multirow[t]{2}{*}{ Amitriptyline } & Recommended 157,238 & $\mathrm{Na}_{\mathrm{v}} \mathrm{I} .7$ blockade $\mathrm{b}^{107,259}$ \\
\hline & Impact: blockade of $\mathrm{Na}_{\mathrm{v}} \mid .7^{239,243,244}$ and $\mathrm{Na}_{\mathrm{v}} \mid .8^{244}$ & $\mathrm{Na}_{\mathrm{v}} \mathrm{I} .8$ blockade $^{34,35}$ \\
\hline \multirow[t]{2}{*}{ Ibuprofen } & Preferred by patients ${ }^{157}$ & $\mathrm{Na}_{\mathrm{v}} \mathrm{I} .7$ blockade $\mathrm{b}^{107,259}$ \\
\hline & Impact: blockade of $\mathrm{Na}_{\mathrm{v}} \mid .7^{253-255}$ and $\mathrm{Na}_{\mathrm{v}}$ I.8 systemically $y^{255}$ and topically & $\mathrm{Na}_{\mathrm{v}} \mathrm{I} .8$ blockade $^{34,35}$ \\
\hline \multirow[t]{2}{*}{ Gabapentin } & Helpful (Cochrane review) ${ }^{249}$ & $\mathrm{Na}_{\mathrm{v}} \mathrm{I} .7$ blockade $\mathrm{b}^{107,259}$ \\
\hline & Impact: blockade of $\mathrm{Na}_{\mathrm{v}} \mid .7^{250,251}$ & \\
\hline \multirow[t]{2}{*}{ Pregabalin } & Helpful 157,249 & $\mathrm{Na}_{\mathrm{v}} \mathrm{I} .7$ blockade $\mathrm{b}^{107,259}$ \\
\hline & Effect $\mathrm{Na}_{\mathrm{v}}$ I.7-associated ${ }^{252}$ & \\
\hline \multirow[t]{2}{*}{ Tramadol } & Second-line treatment ${ }^{157}$ & Sodium-channel blockade ${ }^{34-36}$ \\
\hline & Impact: sodium-channel blockade & \\
\hline
\end{tabular}

Abbreviations: DRGs, dorsal root ganglia; FMS, fibromyalgia syndrome; $\mathrm{Na}_{\mathrm{v}}$, voltage-gated sodium channels.

this could contribute to general hypersensitivity and chronic widespread pain. ${ }^{84}$ The inflammatory components of FMS have also been regarded as an expression of mitochondrial dysfunction, and thus an improvement in mitochondrial function may be a new therapeutic approach. ${ }^{85}$ In turn, ambroxol has an impact on mitochondria: it inhibits lipid peroxidation in hepatic mitochondria by $96 \%,{ }^{59}$ prevents toxic increase in mitochondrial membrane permeability,${ }^{60}$ and in animal models improves mitochondrial oxidative damage. ${ }^{61}$

Another investigation also pointed to mitochondrial dysfunction: stimulation of mononuclear cells of healthy subjects resulted, as expected, in significantly increased cytokine levels in contrast to unstimulated cultures. In FMS patients, however, the concentrations of most cytokines were lower. Behm et $\mathrm{al}^{11}$ interpreted this observation as an impairment of cell-mediated immunity in FMS patients. On the other hand, there are findings that ambroxol could protect immunocompetent cells from dysfunction ${ }^{86}$ and appears to strengthen cell-mediated immunity. ${ }^{87}$

\section{Mast cells}

In comparison to healthy subjects, patients with FMS have more mast cells in the skin. ${ }^{53,88}$ The significance of this finding for the pathogenesis of FMS has been classified as unclear by 


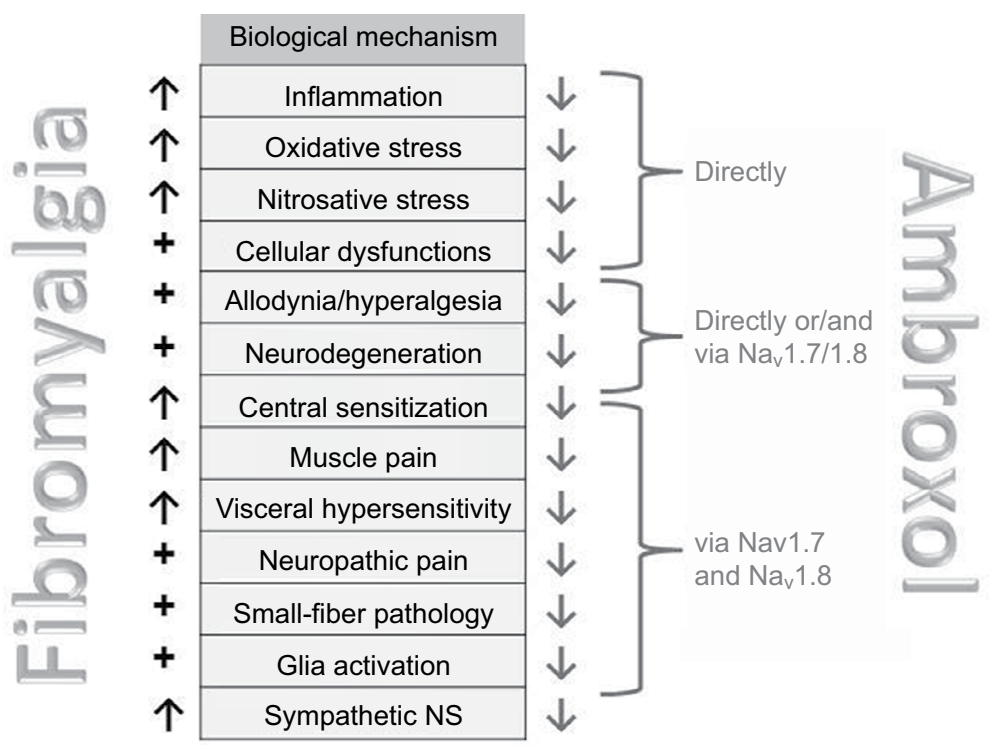

Figure 4 Mechanisms involved in fibromyalgia and influenced by ambroxol (see Tables I-3). Abbreviations: $\mathrm{Na}_{v}$, voltage-gated sodium channels; $\mathrm{NS}$, nervous system.

some authors ${ }^{88}$ whereas others have used this as a basis for classifying FMS as a mast cell-associated disorder. ${ }^{53}$ If this latter interpretation were to hold true, the fact that ambroxol inhibits secretion from mast cells $\mathrm{s}^{54-56}$ would be of considerable importance. At least in pain models on ischemia/reperfusion, there is clearly a close relationship between cardiac mast cells and C-fibers. ${ }^{89}$ Furthermore, mast cells play an important role in chronic urticaria, and in one study a surprising $70 \%$ of 126 urticaria patients also suffered from FMS. Torresani et $\mathrm{al}^{90}$ discussed whether neuropeptides released owing to degranulation of increased numbers of mast cells in FMS patients may stimulate nerve endings, and chronic urticaria may thus occur as a result of skin neuropathology in FMS. Recently, it was demonstrated that cortiocotropinreleasing hormone and substance $\mathrm{P}$ are increased in FMS and stimulate release of IL6 and TNF $\alpha$ from mast cells. ${ }^{91}$ Both IL $6^{44,46,47}$ and TNF $\alpha^{44-46,48-52}$ are reduced by ambroxol. However, there are open questions remaining: therapeutic use of the mast-cell stabilizer ketotifen does not show significant differences between groups with regard to pain and Fibromyalgia Impact Questionnaire (FIQ) scores, which raises the question whether mast cells do play a major role in FMS. ${ }^{88}$

\section{Chronic psychological, oxidative, and nitrosative stress Chronic stress and cortisol}

Since it is still not clear how chronic stress influences visceral and somatosensory pain regulation, both types of hyperalgesia were investigated in an animal model: the authors demonstrated that chronic stress also led to upregulation of the $\mathrm{Na}_{\mathrm{v}} 1.8$ channel. ${ }^{92}$ It was shown that both visceral and somatosensory hyperalgesia and the increased expression of $\mathrm{Na}_{\mathrm{v}} 1.8$ normalized after 3 days without stress: this related to sodium channels in the dorsal root ganglion (DRG) neurons of those segments, which are responsible for the pelvic viscera. ${ }^{92}$ This may for example explain the associated visceral symptoms in FMS, and in turn suggest a therapeutic approach using ambroxol with its selective $\mathrm{Na}_{\mathrm{v}} 1.8$ blockade. This applies even more if FMS is considered a stress-mediated disorder, ${ }^{5,93}$ in which the overexpression of $\mathrm{Na}_{\mathrm{v}} 1.8$ is not further downregulated and a receptor blockade would gain even greater importance.

Since pain and fatigue as core symptoms of FMS are also characteristic of disorders with reduced cortisol levels, it has been hypothesized that there may also be reduced cortisol levels (caused by fatigue?) in FMS. Although glucocorticoid tests in 12 female FMS patients showed no reductions in daytime cortisol profile in comparison to 15 controls, they did however show reduced sensitivity of glucocorticoid-receptor function; this was considered a pathophysiologically relevant finding for FMS by Geiss et al. ${ }^{94}$ In this context, the fact that the anti-inflammatory potency of ambroxol is comparable to dexamethasone $\mathrm{e}^{46,51,95}$ and beclomethasone ${ }^{96}$ without requiring glucocorticoid receptors is not necessarily relevant, but nevertheless worthy of note.

\section{Oxidative stress}

The findings concerning oxidative stress in fibromyalgia are currently still inconsistent. In particular, it is not clear whether the disease is caused by oxidative stress.$^{97}$ Enhanced oxidative 
stress mediated by free radicals is however evident in FMS and leads to increased cytokine expression. There is much evidence that suggests that increased oxidative stress leads to increased severity of FMS symptoms. ${ }^{81,97}$ In particular, a positive correlation has been observed between FIQ and increased lipid peroxidation. ${ }^{81}$ Malondialdehyde is a toxic metabolite of lipid peroxidation, and significantly increased levels of this metabolite have repeatedly been found in patients with FMS. ${ }^{22-24}$ Ambroxol inhibits this harmful lipid peroxidation..$^{59,98,99}$ Furthermore, the enzyme xanthine oxidase correlates with the severity of muscular pain in $\mathrm{FMS}^{100}$ and is also reduced by ambroxol. ${ }^{45} \mathrm{~A}$ similar relationship has been shown for other antioxidative substances: decreased levels of catalase have been shown for FMS, ${ }^{80,81}$ and these levels are enhanced by ambroxol. ${ }^{62,101}$ The same applies to glutathione peroxidase, ${ }^{45}$ which is also decreased in FMS patients and enhanced by ambroxol. ${ }^{80,81}$ There are apparently lower levels of the intracellular antioxidative enzyme superoxide dismutase in FMS patients, ${ }^{23,24,80}$ ambroxol can also lead to increased levels of this enzyme. ${ }^{45,98,101-104}$ Skin biopsies of FMS patients also show increased levels of oxidative metabolites that correlated with the severity of pain and inflammation. ${ }^{57}$ Both are relevant for the development of peripheral nerve damage, which has also been observed in FMS and may be the cause of allodynia. Since investigations on DRG neurons of mice recently suggested that nociceptor hyperexcitability induced by oxidative stress is primarily mediated via sensitization of the ambroxol-inhibited $\mathrm{Na}_{\mathrm{v}} 1.8$ channel type, ${ }^{105}$ Schlüter and Leffler ${ }^{106}$ investigated the influence of the strong oxidant chloramine T. They confirmed these findings, which were more pronounced for the $\mathrm{Na}_{\mathrm{v}} 1.8$ than for the $\mathrm{Na}_{\mathrm{v}} 1.7$ subtype, which however is also inhibited by ambroxol. ${ }^{107}$

In summary, the balance of oxidants and antioxidants appears to be disturbed in FMS, and increased levels of free radicals are possibly responsible for development of the disease. ${ }^{24,80}$ Fibromyalgia can thus also be understood as an oxidative disorder. ${ }^{24}$ Understandably, rheumatologists are requesting further investigations into the effects of radical scavengers, ${ }^{100}$ and ambroxol is known to be one such scavenger. ${ }^{44,60,62-65}$

Oxidative stress and lipid peroxidation do not only occur in FMS and depression. Some of the products resulting from these processes are in addition predictors for neurodegeneration; this may be the reason for associations of both indications with neuropathic pain. ${ }^{108}$ Oxidative damage of DNA may be important in this context. ${ }^{109}$ As a strong radical scavenger ${ }^{44,60,62-65}$ and inhibitor of lipid peroxidation, ${ }^{59,98,99}$ ambroxol may thus counteract neurodegenerative changes during disease progression in FMS.

Both ambroxol and melatonin are able to protect from lipid peroxidation. ${ }^{10}$ Melatonin levels that are too low may have a negative impact in FMS. ${ }^{111}$ Since melatonin is one of the targets of the latest strategies in the development of drugs for FMS, ${ }^{112,113}$ and this is based on being a radical scavenger that functions like a strong antioxidant, ${ }^{114}$ the same may also apply to ambroxol.

\section{Nitrosative stress}

Nitrosative stress is caused by reactive nitrogen species, eg, nitrogen monoxide (NO) and its product peroxynitrite. These harmful and highly reactive nitrogen compounds are involved in cellular dysregulation. It is assumed that nitrosative stress is involved in neurological and inflammatory disorders. This has also been demonstrated for FMS. ${ }^{84,115}$ It has been suggested that NO is involved in the pathophysiology of FMS, ${ }^{97,116}$ may be responsible for pain sensitivity, ${ }^{117}$ and correlates with pain severity. ${ }^{118}$ In addition, NO levels correlate with the FIQ score. ${ }^{119}$ On this basis, Cimen et al ${ }^{120}$ have requested the search for inhibitors of nitric oxide synthase (NOS) for FMS treatment, since this enzyme catalyzes the (unfavorable) formation of NO. The same effect, however, is also achieved with ambroxol: the compound inhibits the production and activity of NO..$^{44,121-123}$

\section{Sex hormones}

Since FMS primarily affects women, there is reason to presume that sex hormones play an important role. Estradiol $\left(E_{2}\right)$ has a key function in pain modulation. The effects of $E_{2}$ are mediated via estrogen receptors (ERs). ${ }^{124,125}$ ERs (ER $\alpha$, $\mathrm{ER} \beta$ ) and $\mathrm{Na}_{\mathrm{v}} 1.8$ may be expressed in DRG neurons. In knockout mice for $\mathrm{ER} \beta, \mathrm{Na}_{\mathrm{v}} 1.8$ is upregulated, ${ }^{124}$ and in addition voltage-gated sodium channels are inhibited by $\mathrm{E}_{2} \cdot{ }^{125} \mathrm{In}$ principle, hormone deficiency may thus contribute to hyperexcitability in fibromyalgia. Hormone-replacement therapy, however, does not lead to an improvement in symptoms, ${ }^{126}$ and sex-hormone deficiency has not been demonstrated for FMS. ${ }^{127,128}$ Nevertheless, ambroxol is able to inhibit experimentally upregulated $\mathrm{Na}_{\mathrm{v}} 1.8$ sodium channels ${ }^{34-36}$ or those sodium channels that are functionally insufficiently blocked by $\mathrm{E}_{2} \cdot{ }^{34}$ The compound is an approximately 12 -fold stronger inhibitor of $\mathrm{Na}_{\mathrm{v}} 1.8$ than lidocaine and 40 -fold stronger if neuronal sodium channels in general are considered. ${ }^{36}$ Of note, lidocaine has already been used successfully for FMS. ${ }^{129-132,336}$ 


\section{Muscular pain}

Both peripheral and central sensitization processes are involved in the transition from acute to chronic muscular pain. ${ }^{133-135}$ One of the currently leading theories suggests that acute stimulation of specific nociceptors binding isolectin $\mathrm{B}_{4}\left(\mathrm{IB}_{4}\right)$ may lead to long-term hypersensitivity of nociceptors. Consequently, a lasting increase in TTX-r sodium-channel activity (such as $\mathrm{Na}_{\mathrm{v}}$ 1.8) is required, in order to achieve long-term changes in intracellular signalling. ${ }^{136} \mathrm{Na}_{\mathrm{v}} 1.8$ inhibition with ambroxol would in this case be a preventive approach. Recent studies again confirmed the importance of $\mathrm{IB}_{4}$-positive muscular nociceptors for chronic muscular pain, ${ }^{137,138}$ thereby confirming older and similar research results. ${ }^{139,140}$ Tissue hyperacidity in muscles owing to ischemia and inflammation has a decisive impact on the initiation and progression of chronic muscular pain. ${ }^{141,142}$ Acid-sensing ion channel (ASIC)-3 and transient receptor-potential cation-channel subfamily $\mathrm{V}$, member 1 are involved in the activation of muscular nociceptors, the induction of central sensitization, and chronic muscular pain. ${ }^{143-145}$ ASIC3 has been demonstrated to play a major role in triggering acid-induced chronic muscular pain. ${ }^{139,146}$ Its activation again increased $\mathrm{Na}_{\mathrm{v}} 1.8$ activity, with essential development of longlasting hyperalgesia and chronic widespread muscular pain in a mouse model of fibromyalgia. ${ }^{41}$ Since to date, ASIC 3 cannot be specifically blocked, Chen et al ${ }^{41}$ considered selective blockade of $\mathrm{Na}_{\mathrm{v}} 1.8$ a good treatment option for chronic muscular pain with ischemic conditions.

According to their own reports, patients affected by FMS in the US ${ }^{147}$ and Germany ${ }^{148}$ had only minor benefit from antiinflammatory treatment. Correspondingly, in their microdialysis investigations in muscles of FMS patients, Christidis et al ${ }^{149}$ detected no changes in the proinflammatory cytokines IL1 $\beta$, IL6, IL8, or TNF $\alpha$. In contrast, another cytokine, MCP1, not only occurs with increased levels in the blood of fibromyalgia patients ${ }^{150}$ but is also supposed to induce persistent muscular hyperalgesia and chronic sensitization. ${ }^{151}$ Should this be of relevance for FMS, ambroxol may again be of therapeutic benefit, since it can contribute to a reduction in MCP1..$^{51,95,152}$ Muscular pain in FMS patients is also explained by mitochondrial dysfunction in muscular cells. ${ }^{84}$ As just described, this could also be improved by ambroxol. ${ }^{59-61}$ Furthermore, the ambroxol-reduced oxidative-toxic enzyme xanthine oxidase ${ }^{45}$ correlates with muscular pain severity in FMS. ${ }^{100}$

\section{Neuropathic pain and small-fiber pathology}

The latest research on FMS pain has shown that at least in a subgroup of patients, a neuropathic component is involved. ${ }^{67,153-155}$ Changes in small nerve fibers and a high PainDetect score suggest this, ${ }^{156}$ even though this questionnaire has not been validated for the disease. ${ }^{155} \mathrm{In}$ a comparison of diabetic polyneuropathy with FMS, approximately $30 \%$ of patients showed an overlap of sensory profiles, whereas other distinct profiles were disease-specific. ${ }^{156}$ Furthermore, it is noteworthy that many drugs used for the treatment of FMS $^{157}$ are also used for neuropathic pain. ${ }^{158}$

There is increasing knowledge in particular about changes in small nerve fibers. In this respect, Uçeyler and Sommer ${ }^{159}$ and Doppler et a ${ }^{160}$ considered it important to use the term "small-fiber neuropathology" and distinguish this from "small-fiber neuropathy". Interestingly, Doppler et al ${ }^{160}$ demonstrated significantly reduced average axon diameters in skin biopsies of 32 FMS patients compared to 12 patients with small-fiber neuropathy and 40 healthy controls. It appears that quite different pathophysiological mechanisms lead to the development of small-fiber degeneration and/or regeneration. ${ }^{66,161}$ In FMS, not only changes in peripheral small fibers but also in the eye (which belongs to the CNS) occur. ${ }^{162,163}$ Controlled investigations with skin biopsies ${ }^{67}$ and laser-evoked potentials ${ }^{164}$ showed reduced intraepidermal nerve-fiber density in FMS patients compared to healthy controls, and thereby also support the theory of at least a partial neuropathic origin of pain. As mentioned earlier, we were able to report clinical efficacy of topical ambroxol for neuropathic pain in previous publications; ${ }^{27-29,165}$ however, experimentally there is also no doubt that ambroxol exerts systemic effects as well. ${ }^{34,69-71}$ In small-fiber neuropathy, primarily small unmyelinated peripheral neurons are damaged; in other words, nociceptive C-fibers of the skin primarily expressing $\mathrm{Na}_{\mathrm{v}} 1.8 \cdot{ }^{37-40,166-168}$ In animal models, approximately $50 \%$ of the C-fibers express just these $\mathrm{Na}_{\mathrm{v}} 1.8$ channels that are inhibited by ambroxol, ${ }^{166}$ and their numbers even increase under painful conditions. ${ }^{167,168}$ In addition, at least in patients with pure small-fiber neuropathy, gain-of-function mutations of $\mathrm{Na}_{\mathrm{v}} 1.8$ have been detected. ${ }^{169-172}$ Furthermore, $\mathrm{Na}_{\mathrm{v}} 1.8$ can be increasingly expressed in case of distal degeneration of small-diameter peripheral axons and thus contribute to central sensitization. ${ }^{171}$ Owing to its mechanism of action, ambroxol can be expected to provide some protection from this type of sensitization in FMS.

Finally, and as an indication for neuropathic pain involvement, patients with FMS show low tolerance of cold water, ${ }^{173}$ whereas the ambroxol-inhibited $\mathrm{Na}_{\mathrm{v}} 1.8$ channel is of particular importance for cold pain. ${ }^{38,174}$ In the animal model, ambroxol suppressed cold allodynia by approximately $75 \%{ }^{69}$ 


\section{Central sensitization, allodynia, and hyperalgesia Central sensitization}

It is widely accepted among researchers that the biological component of FMS is associated with long-term or even permanent functional changes of the nociceptive nervous system. ${ }^{175,176} \mathrm{~A}$ systematic review on central sensitization in fibromyalgia evaluated 13 studies concerning functional changes (via functional magnetic resonance imaging). Nociceptive stimuli led to more pronounced but otherwise comparable activation of the pain matrix in FMS patients compared to controls. ${ }^{42}$ Eight studies investigating structural changes (via voxel-based morphometry) provided moderate evidence for a correlation between central sensitization and a decrease in gray matter in certain regions. ${ }^{42}$ In their experiments with thermal stimulation, Vierck et al ${ }^{177}$ demonstrated abnormally prolonged sensitivity in FMS patients, which again was interpreted as an indication of central sensitization and a specific influence of widespread chronic pain from deep somatic tissue. Visceral hyperalgesia, somatosensory hyperalgesia, and increased expression of $\mathrm{Na}_{\mathrm{v}} 1.8$ are closely associated. ${ }^{92}$ Correspondingly, $\mathrm{Na}_{\mathrm{v}} 1.8$-selective antagonists (other than ambroxol) have analgesic efficacy in acid-induced chronic widespread-pain models ${ }^{178}$ and lead to a reduction in allodynia and hyperalgesia ${ }^{179}$ in animal models of neuropathic and inflammatory pain. Following experiments in a fibromyalgia animal model, Chen et $\mathrm{al}^{41}$ thus generally considered selective $\mathrm{Na}_{\mathrm{v}} 1.8$ blockers, one of which was ambroxol, as a good choice of treatment of chronic pain and for limitation of central sensitization.

\section{Allodynia and hyperalgesia}

Allodynia and hyperalgesia are common signs in FMS. ${ }^{180-182}$ Sleep deprivation can cause these signs, ${ }^{183}$ as well as oxidative stress, mitochondrial dysfunction, and inflammation, with the consequence of peripheral nerve damage. ${ }^{57}$ Functional brain-imaging studies have provided compelling evidence for abnormal pain processing in FMS correlating with patients' hyperalgesia or allodynia. ${ }^{184}$ FMS patients experience prickling and touch-evoked allodynia at the same frequency as patients with diabetic polyneuropathy. ${ }^{156}$ Furthermore, FMS patients show lower heat-pain and cold-pain thresholds than controls, ${ }^{185,186}$ and severe thermal allodynia following cutaneous heat exposure has been reported. ${ }^{187}$ Systemic ambroxol, however, suppressed heat hyperalgesia by $100 \%$ in an animal model. ${ }^{69}$

Pain symptoms in FMS animal models are more likely associated with dysfunction of biogenic amine-mediated CNS pain control compared to pain due to nerve injuries. ${ }^{188}$ However, rats in an FMS model showed hypersensitivity to tactile muscle pressure and cold stimuli. Once again in an animal model, ambroxol reduced cold hyperalgesia and mechanical allodynia by approximately $75 \%{ }^{69}$ The observation that ambroxol also reduces mechanical allodynia in an experimentally induced inflammation in rats by approximately two-thirds ${ }^{68}$ suggests that the antiallodynic analgesic effect is not necessarily restricted to neuropathic pain. It is indeed possible to reduce mechanical allodynia in monoarthritis pain with ambroxol by $50 \%{ }^{69}$

The $\mathrm{Na}_{\mathrm{v}} 1.8$ channel is detected mainly in $\mathrm{C}$ - or $\mathrm{A} \delta$-fibers and neurons of the posterior horn, ${ }^{37-40}$ although it is also expressed in A $\beta$-fibers ${ }^{68,174,189-191}$ Since in chronic inflammation, which is also discussed for FMS, the excitability of $\mathrm{Na}_{\mathrm{v}} 1.8$ is shifted to hyperpolarization, this contributes to allodynia, and a blockade using ambroxol should then have a particularly pain-relieving effect. For completeness, it should not go unmentioned that the intrathecal administration of ambroxol has also led to an antiallodynic effect in animal experiments. ${ }^{68}$ Furthermore, simultaneous therapy with ambroxol reduces heat and cold hyperalgesia due to oxaliplatin in an animal model, which the authors felt to be transferable to humans. ${ }^{192}$ In summary, there is plenty of evidence for a reduction in FMS hyperalgesia or allodynia following ambroxol treatment.

\section{Sympathetic nervous system, glia, and dopamine}

\section{Sympathetic nervous system}

One indication of sympathetic nervous system involvement in FMS was detected in a subgroup of obese female FMS patients by Okifuji et al. ${ }^{193}$ They found a strong correlation between body-mass index and levels of the sympathomimetic epinephrine and IL6. The latter agent is reduced by ambroxol. ${ }^{44,46,47}$ Investigations into heart-rate variability have shown persistent excessive sympathetic activity in FMS. ${ }^{194}$ Norepinephrine injections can induce FMS pain. ${ }^{195}$

In 2009, Martinez-Lavin and Solano ${ }^{196}$ presented a hypothesis on FMS in which sodium channels play a major role, and the authors suggested that sodium-channel blockers could become a therapeutic option for FMS pain. This renders the sodium-channel blocker ambroxol interesting for therapy: sodium channels localized in DRGs have a molecular gatekeeper function for impulses from peripheral nociceptors. Trauma, infection, or other factors may induce neuroplasticity via overexpression of sympathetic fibers and sodium channels in DRGs. The authors considered enhanced DRG excitability to play a key role in FMS pain. Since DRGs 
are potential sites of sympathetic-nociceptive short circuits, individuals who are genetically predisposed for sympathetic hyperactivity and those with inherent sodium channelopathies would be at risk of developing FMS. In addition, stressful environmental conditions in today's society could possibly contribute to sympathetic hyperactivity, and antiinflammatory vagus-nerve activity might not be sufficient to counteract this. If FMS is interpreted in this context as a sympathetically maintained neuropathic pain syndrome, sodium-channel blockers gain importance as a therapeutic option for FMS pain. ${ }^{196}$ At least, the sodium channel $\mathrm{Na}_{\mathrm{v}} 1.8$, which is selectively blocked by ambroxol, is of importance in the sympathetic nervous system. Schofield et al ${ }^{197}$ demonstrated that $\mathrm{Na}_{\mathrm{v}} 1.8$ occurs on the sympathetic superior cervical ganglion and can be blocked. Facer et al ${ }^{198}$ demonstrated the presence of $\mathrm{Na}_{\mathrm{v}} 1.8$-immunoreactive sensory nerve fibers in the human myocardium, which are - interestingly with regard to sympathetic function - frequently closely associated with small capillaries.

\section{Glia activation and dopamine}

Apart from obviously enhanced sympathetic activity, FMS patients also have increased IL8 levels in cerebrospinal fluid, ${ }^{199,200}$ which in principle can be reduced by ambroxol. ${ }^{96,201-205}$ Kadetoff et $\mathrm{al}^{200}$ interpreted their findings to be a result of FMS symptoms being mediated by sympathetic activity, rather than being dependent on prostaglandinassociated mechanisms, and considered this supportive of the hypothesis of glia-cell activation in response to pain mechanisms. ${ }^{200}$ Interestingly, intrathecal administration of ambroxol leads to an antiallodynic effect in an animal model without having an impact on peripheral swelling caused by inflammation. ${ }^{68}$ Moon et $\mathrm{al}^{71}$ also concluded that after intrathecal administration of ambroxol that early treatment with an $\mathrm{Na}_{\mathrm{v}} 1.8$ inhibitor may be an important factor in the clinical management of chronic mechanical allodynia during inflammatory or ischemic pain..$^{71}$

Enhanced levels of IL8 have the potential to activate glia cells. ${ }^{206}$ Activated glia cells in turn can also produce new IL8, ${ }^{207}$ which again promotes sympathetically maintained pain. ${ }^{208}$ In addition, activated glia cells can produce IL1 $\beta$ as a result of proinflammatory stimuli, ${ }^{209,210}$ and IL1 $\beta$ is also reduced by ambroxol. ${ }^{44,45}$ Recent research has shown that glia cells maintain neuronal hypersensitivity in DRGs by releasing substances that also act on the immune system. ${ }^{211}$ In addition to peripheral changes, persistent glial activation with resulting central sensitization is also of importance in FMS, which in turn is activated by cytokines from repeated tissue injury. ${ }^{17,212}$
Albrecht et $\mathrm{al}^{213}$ considered glial activation in the brains of FMS patients, which was demonstrated via imaging procedures (positron-emission tomography and magnetic resonance imaging) to be being important in the pathophysiology of the disease. In another investigation, 126 fibromyalgia patients were genotyped and subgroups formed with regard to their binding affinity to translocator protein (TSPO), which is upregulated during glial activation. Those patients with high TSPO-binding affinity reported significantly more pain and FMS symptoms, which again supports glia-related mechanisms in FMS. ${ }^{214}$ This fits with the observation that naltrexone, an inhibitor of microglial activity in the CNS, reduced FMS symptoms in some patients in a small pilot study. ${ }^{215}$

A permanent and robust increase in microglia population also contributes to an overexpression of $\alpha$-synuclein, a small soluble protein in the brain of vertebrates which, among other actions, regulates the release of dopamine. ${ }^{216}$ Su et $\mathrm{al}^{217}$ demonstrated that $\alpha$-synuclein in addition also activates microglia, thereby contributing to the release of proinflammatory molecules. This finding has been supported by other authors. ${ }^{218}$ The release of $\alpha$-synuclein from affected neurons was also increased in an animal model of CNS injury with ischemia-reperfusion, thereby mediating microglia activation. ${ }^{219}$ The protein has neurotoxic effects, and not only leads to the microglia activation described but also to increased dopaminergic neurodegeneration. ${ }^{220}$ Research on the pathophysiology of fibromyalgia is increasingly focusing not only on glia activation but also on the neurotransmitter dopamine. Experimental induction of FMS has demonstrated decreased dopamine levels in both the brain and the spinal cord. ${ }^{221}$ Imaging procedures, however, have pointed to dopamine dysfunction as an important factor in increased pain sensitivity in FMS. ${ }^{222}$ Other authors have also considered dopamine an important neurochemical moderator of FMS pain perception, since their data suggested interrupted dopaminergic neurotransmission in FMS. ${ }^{223}$ It is thus plausible that dopamine receptors are investigational targets for new FMS medications. ${ }^{113}$ It should be pointed out that in this respect, ambroxol leads to a reduction in $\alpha$-synuclein, ${ }^{224} \mathrm{ie}$, reduces just that protein that contributes to both glia activation and dopaminergic neurodegeneration. ${ }^{220}$ For this reason, the medication has also been considered for the treatment of Parkinson's disease. ${ }^{74-76,224}$

\section{Neurodegeneration and neuroregeneration}

A systematic review on imaging studies revealed indications of structural changes in the CNS of fibromyalgia patients. ${ }^{42}$ 
The neurodegenerative findings of small-fiber neuropathology mentioned earlier are not restricted just to the peripheral nervous system either, but have also been reported for the cornea (cranial nerve $\mathrm{V})^{162}$ and axonal nerve injury early in the progression of the disease in the retina of FMS patients, ${ }^{163}$ which belongs to the CNS. It is generally accepted that the regenerative capacity of injured nerves in the CNS is markedly worse than in the peripheral nervous system. Therefore, it is remarkable that neuroregenerative properties in the CNS have recently been described for ambroxol. ${ }^{225}$ During a systematic genetic search for suitable treatment options promoting regenerative neuronal growth, Chandran et $\mathrm{al}^{225}$ found that ambroxol was not just the only one of the tested substances causing eight gene expressions in treated DRG neurons, but also enhanced axonal sprouting from these. Furthermore, they were able to demonstrate real neuroregeneration in the CNS by ambroxol in an optical nerve model in vivo: studies using knockout mice confirmed that systemically administered ambroxol significantly and morphologically improved regeneration of the optic nerve. ${ }^{225}$ It has to be pointed out, though, that despite the fact that ambroxol obviously crosses the blood-brain barrier, ${ }^{79,226}$ brain levels could be too low to cause relevant effects under currently used therapeutic dosages. $^{227}$ This reduces potential side effects, and also a therapeutically desired effect. Whether the mother substance bromhexine, which definitively crosses the blood-brain barrier without $\mathrm{CNS}$ side effects, ${ }^{228}$ could be of additional benefit remains unanswered.

At least in ischemia-induced neurodegeneration, reactive oxygen species have a key function, and ambroxol is able to contribute to the reduction of such ischemia-caused nerve injury. ${ }^{22}$ Oxidative stress and lipid peroxidation occur not just in fibromyalgia and depression. Some of the products resulting from these processes are also predictors of neurodegeneration. ${ }^{108}$ As a strong radical scavenger and inhibitor of lipid peroxidation, ambroxol should under these circumstances counteract neurodegenerative changes during the progression of FMS. This effect of ambroxol has been demonstrated at least for polyneuropathy caused by oxaliplatin. ${ }^{192}$ Oxaliplatin also leads to an increase in inflammatory mediators and oxidative stress, and is thus peripherally neurotoxic. Simultaneous treatment with oral ambroxol in these animal models reduces relevant neuropathic pain, and as a result decreases heat and cold hyperalgesia, and both of these symptoms have also been reported for FMS. ${ }^{154,156,185,186}$ The authors considered these results transferable to humans.

\section{Sodium channels}

There is some evidence that sodium channels are important in FMS. In an investigation of 73 female FMS patients, genetic $\mathrm{Na}_{\mathrm{v}} 1.7$ polymorphism was associated with severe fibromyalgia. ${ }^{26}$ The receptor is assumed to play an important role in pain transmission in DRG neurons in FMS. ${ }^{196} \mathrm{Na}_{\mathrm{v}} 1.7$ subtypes, ${ }^{170,230-233}$ as well as $\mathrm{Na}_{\mathrm{v}} 1.8$ mutations, ${ }^{171,234}$ are also associated with small-fiber neuropathy, and at least one small-fiber pathology appears to be present in a subgroup of FMS. ${ }^{159,160}$ Although there have been reports of $\mathrm{Na}_{\mathrm{v}} 1.7$ gainof-function mutations and even more evidently hypothalamic dysfunction, it is not known whether or not this channel subtype plays a functional role in the hypothalamus with regard to external stressors in man. At least experimentally, however, it can be demonstrated that $\mathrm{Na}_{\mathrm{v}} 1.7$ is upregulated in the CNS in parallel with osmotic stress ${ }^{235}$ and that oxidative stress leads to sensitization of $\mathrm{Na}_{\mathrm{v}} 1.8{ }^{106}$ In gain-of-function mutations of the $S C N 10 A$ gene, which encodes for $\mathrm{Na}_{\mathrm{v}} 1.8$, symptoms with diffuse painful sensory neuropathy, autonomic symptoms and gastrointestinal dysfunction ${ }^{170,171,234,236}$ resemble FMS symptoms and are associated with hyperexcitability of DRG neurons. ${ }^{230}$ Selective sodium-channel blockers are currently unavailable for routine clinical practice. ${ }^{237}$ As presented herein, quite a few medications used for fibromyalgia cause (among other actions) sodium-channel blockade, even though this is aspecific.

More than 500 randomized controlled trials (RCTs) on the treatment of fibromyalgia were already available in 2008. The strongest recommendations of several medical societies were for various antidepressants. ${ }^{238}$ It is remarkable that many tricyclic antidepressants, selective serotonin-reuptake inhibitors, and serotonin-norepinephrine reuptake inhibitors also block sodium channels. ${ }^{239}$ For instance, duloxetine is beneficial for FMS ${ }^{157,238}$ and blocks both $\mathrm{Na}_{\mathrm{v}} 1.7$ and $\mathrm{Na}_{\mathrm{v}} 1.8 .^{240,241}$ The sodium-channel blockade of duloxetine is stronger than that of venlafaxine, which in turn was only attributed minimal effects in a systematic review. ${ }^{242}$ Amitriptyline, which has received a strong recommendation for FMS, ${ }^{157,238}$ also blocks $\mathrm{Na}_{\mathrm{v}} 1.7^{239,243,244}$ and $\mathrm{Na}_{\mathrm{v}} 1.8,{ }^{244}$ or rather generally TTX-r channels (to which $\mathrm{Na}_{\mathrm{v}} 1.8$ belongs) in trigeminal neurons, DRG neurons, and gastrointestinal neurons. ${ }^{245-247}$ On the other hand, paroxetine shows less effect in FMS, ${ }^{157,248}$ and in comparison to amitriptyline only blocks $\mathrm{Na}_{\mathrm{v}} 1.7$ at high concentrations. ${ }^{239}$ Furthermore, gabapentin, which was recommended in a data analysis by Cochrane ${ }^{249}$ also blocks $\mathrm{Na}_{\mathrm{v}} 1.7,{ }^{250,251}$ and pregabalin, which was also classified as beneficial, ${ }^{157,249}$ reduces paroxysmal neuropathic itch in patients with a variant of the 
SCN9A gene, which encodes for $\mathrm{Na}_{\mathrm{v}} 1.7 .{ }^{252}$ Even ibuprofen, which is often preferred by patients, ${ }^{157}$ blocks the channel subtypes $\mathrm{Na}_{\mathrm{v}} 1.7^{253-255}$ and $\mathrm{Na}_{\mathrm{v}} 1.8$ after systemic ${ }^{255}$ and topical administration. ${ }^{254}$ Finally, tramadol, which is recommended as second-line treatment, ${ }^{157}$ also blocks sodium channels. ${ }^{256,257}$ An interesting fact in this respect is that at least peripheral analgesia with opioids is partly mediated via $\mu$-receptors on primary afferent $\mathrm{Na}_{\mathrm{v}} 1.8$-positive neurons. ${ }^{258}$

Although much evidence points to the importance of sodium channels in FMS and promising RCTs have been conducted, the relevance of sodium channel-blocking antiepileptic drugs cannot be confirmed: in a systematic review, Wiffen et $\mathrm{al}^{249}$ found no valid indications that the sodiumchannel blockers of this group of substances achieved aboveaverage therapeutic results in FMS. It tends to be forgotten, however, that to date generally, no specific analgesics for the blockade of the main targets $\mathrm{Na}_{\mathrm{v}} 1.7$ and $\mathrm{Na}_{\mathrm{v}} 1.8$ are available for treatment, and for this very reason could not be assessed in this review. Thus far, none of the compounds used for neuropathic pain (including local anesthetics, antidepressants, and antiepileptics) shows relevant selectivity for $\mathrm{Na}_{\mathrm{v}} 1.8$ that would be comparable to ambroxol. ${ }^{34,35}$ Should the blockade of $\mathrm{Na}_{\mathrm{v}} 1.8$ and/or $\mathrm{Na}_{\mathrm{v}} 1.7$ be an important treatment approach for FMS, efficacy of ambroxol is very likely: not only $\mathrm{Na}_{\mathrm{v}} 1.8$ but also $\mathrm{Na}_{\mathrm{v}} 1.7$ is selectively blocked by ambroxol, ${ }^{107,259}$ and this blockade is even more pronounced in man than in rats. ${ }^{107}$

\section{Inflammatory mediators Cytokines}

Independent of sodium-channel blockade or antineuropathic effects, ambroxol should be able to reduce nociceptive pain via its anti-inflammatory properties. This has also been reported by us for topical ambroxol in a case series of pain patients. ${ }^{29}$ In addition, it has been shown in humans for acute sore throat ${ }^{260,261}$ and experimentally demonstrated. . $2,33,46,68,69,262$ Ambroxol exerts its comprehensive anti-inflammatory properties, for example, via inhibition of many proinflammatory cytokines. ${ }^{32}$

The general importance of cytokines in the induction and maintenance of pain has been well demonstrated in both animal models and pain syndromes in humans, ${ }^{263}$ including FMS. ${ }^{12,13,264}$ Cytokines can also contribute to the origin of pain in the CNS, and spinal cytokines can exert an external impact on peripheral pathology by influencing the efferent neuronal system, with effects on peripheral tissue. ${ }^{265}$ They are also important mediators of neuropathic pain, ${ }^{266-268}$ which is also reduced by ambroxol (as already reported). Cytokines also have an impact on changes in the hypothalamic-pituitaryadrenocortical axis, ${ }^{269-271}$ and thereby on clinical symptoms, such as hyperalgesia, fatigue, sleep disorders, allodynia, adrenocortical hormone-associated disorders, stress responses, anxiety, muscular pain, and cognitive dysfunction; ${ }^{13,200}$ all these are symptoms associated with FMS. ${ }^{19-21}$ The diverse and well-documented impact of ambroxol on cytokines is likely to be of major relevance.

\section{Interleukin 6 and interleukin 8}

In particular proinflammatory and thus pain-inducing IL6 and IL8, which are both reduced by ambroxol, have clinical relevance in FMS. During the past 10 years, approximately 100 of 140 studies on FMS have demonstrated changes in inflammatory mediators and associated these with the pathogenesis and clinical signs of the disease. Several studies observed increased serum levels of IL6 $6^{14,199,200,272}$ or IL8. ${ }^{199,200,273-275}$ A systematic review conducted in 2011 reported evidence for higher serum levels of these cytokines, as well as for IL1RA in FMS, but no confirmed changes in IL1 $\beta$, IL4, IL10, MCP1, or TNF $\alpha .^{12}$

Even before the observation of a real correlation of the intensity of the disease with IL6 und IL8 levels, these were repeatedly reported as being associated with the clinical symptoms of FMS. ${ }^{13,276,277}$ For instance, Mendieta et al ${ }^{276}$ demonstrated that both IL6 and IL8 correlated with clinical psychiatric scores, and considered these interleukins as particularly constant inflammatory mediators in FMS, with their levels significantly correlating with the severity of symptoms.

However, serum concentrations do show large variability, as demonstrated in a systematic analysis by Uçeyler et al. ${ }^{12}$ In particular, a disturbed balance of proinflammatory and anti-inflammatory cytokines is likely to play a role in the origin and maintenance of FMS-related pain. ${ }^{263}$ Their pathophysiological role continues to be disputed, though. ${ }^{12,16,17}$ In contrast to other authors, Ranzolin et $\mathrm{al}^{278}$ did not discover differences in IL6 or IL8 in FMS patients compared to healthy controls in a recent prospective controlled study. Reasons for many partially contradictory findings concerning cytokines are multiple impact factors, such as circadian rhythmicity and influences from depression, physical activity, and infections, which were frequently not clearly assessed in the studies. In addition, drugs can have an impact on cytokines, such that cytokines vary in subgroups or during the progression of the disease. In a systematic investigation of ambroxol for the treatment of fibromyalgia, these factors will definitely need to be considered, at least for this partial effect of the compound. 


\section{Interleukin 6}

During the last 10 years, numerous studies have demonstrated higher serum levels of IL6 in FMS, ${ }^{14,91,199,200,272}$ and this has been confirmed in a systematic review and meta-analysis. ${ }^{12}$ Since IL6 not only has algesic effects but is also involved in the development of hyperalgesia, ${ }^{279}$ fatigue, and depression, ${ }^{13,14}$ it can be assumed to have a role in the modulation of FMS symptoms. ${ }^{208}$ As it is very difficult to limit neuronal hyperexcitability caused by IL6, this interleukin obviously plays a major role during the chronification process and in the poor response of some pain conditions to treatment. ${ }^{280}$ With robust data on increased IL6 levels in FMS, there are also equally robust data confirming that ambroxol reduces both the release and levels of IL6. ${ }^{44,46,47,205}$ In a model on acute lung injury, this was demonstrated with comparable significance to dexamethasone-treated animals. ${ }^{46}$

\section{Interleukin 8}

In the aforementioned review, Uçeyler et al ${ }^{12}$ also demonstrated higher serum and plasma levels of IL8. These findings were repeatedly confirmed thereafter. ${ }^{199,200,273,274,277}$ Ang et al ${ }^{150}$ found a significant correlation of increased IL8 levels with pain severity using the Brief Pain Inventory (BPI): they were able to correlate each change in pain intensity according to BPI with a corresponding increase in IL8. Using a highly sensitive method, Xiao et a ${ }^{277}$ supported the assumption of inflammatory changes in FMS by demonstrating an elevated level of the inflammatory marker CRP in 105 FMS patients compared to 61 healthy controls. The elevated CRP values also showed a significant correlation with IL8 levels. Furthermore, Sturgeon et al ${ }^{93}$ demonstrated a significant correlation between IL8 levels and pain catastrophizing, anxiety, and postmenopausal depression. IL8 was also associated with pain and sleep disorders. ${ }^{273}$ In a comparison of cerebrospinal fluid findings in rheumatoid arthritis and FMS, Kosek et al ${ }^{199}$ demonstrated higher IL8 levels in FMS patients. Kadetoff et $\mathrm{al}^{200}$ also demonstrated higher cerebrospinal fluid and serum concentrations of IL8 in fibromyalgia, an overall constellation that the authors interpreted as an expression of sympathetic activity. In an animal model, Moon et $\mathrm{al}^{71}$ correspondingly showed that intrathecal ambroxol inhibited mechanical allodynia and thermal hyperalgesia in a dosedependent manner. It can be assumed that a reduction in IL8 is involved: in vitro as well as in vivo, both the release and detectable concentrations of IL 8 are reduced by ambroxol, a fact that has been repeatedly shown. ${ }^{47,96,201-205}$ This is probably an important finding concerning this "perhaps most important interleukin" in FMS.

\section{IL I-receptor antagonist}

IL1RA is an inhibitor produced by the body that slows down and finally stops the action of the proinflammatory IL1 and IL1 $\beta$ by binding at their site on the IL1 receptor. Increased serum levels of IL1RA in FMS have been demonstrated in many studies; ${ }^{12,199}$ however, the proinflammatory interleukins "to be regulated" - IL1 and the highly reactive IL1 $\beta$ - do not at all appear to show elevated serum levels in FMS. ${ }^{12,200}$ In contrast to this, however, Imamura et al ${ }^{281}$ detected similarly elevated levels of IL1 $\beta$ in a comparison of FMS patients to osteoarthritis patients, with comparable duration of disease and pain intensity. Using questionnaires and plasma analyses of 50 FMS patients, Menzies et al ${ }^{19}$ demonstrated a negative correlation between subjective stress and IL1 $\beta$ levels. Therefore, possibly just the fact that no elevated levels of IL1 or IL1 $\beta$ can be detected is an expression of severe FMS symptoms or for long duration of the disease. For instance, this may be the reason that elevated levels of IL1 $\beta$ in skin have indeed been detected, but only in a subgroup of FMS patients. ${ }^{43}$ The impaired balance between IL1 and IL1RA remains to be clarified. It is a fact, however, that ambroxol has a major impact: it has been well demonstrated to reduce IL1 ${ }^{44,45,48,51}$ and IL1 $\beta,{ }^{44,45}$ and thus should have a positive preventive effect, at least in cases of initially elevated levels, if present.

\section{Interleukins 4 and 10}

Investigations have shown decreased levels of the antiinflammatory and thus "analgesic" cytokines IL4 and IL10 in FMS in comparison to healthy controls. ${ }^{18}$ In a 2011 review, however, the same research group could not detect clear evidence of serum differences in these two interleukins. ${ }^{12}$ Mendieta et $\mathrm{al}^{276}$ also recently reported no relevant changes in serum levels of IL10 in FMS.

In contrast to this, other authors have demonstrated elevated IL10 levels ${ }^{13,278,281,282}$ and a significant correlation of these with FIQ scores. ${ }^{283}$ IL10 is also increased in the cerebrospinal fluid of FMS patients in comparison to patients with rheumatoid arthritis. ${ }^{199}$ Under ambroxol treatment in experimental stimulation of human alveolar macrophages, IL10 was not elevated, in contrast to IL12, ${ }^{87}$ and the same applied after bacterial stimulation. ${ }^{284}$ Ambroxol thereby promoted a reduced cytokine response after exogenous inflammation and strengthened cell-mediated immunity by shifting the "local balance" toward IL12. ${ }^{87}$ Following exposure to allergens in an artificially sensitized respiratory tract in an animal model, however, ambroxol induced an increase in IL10 in a "protective" manner. ${ }^{285}$ 
Yigit et $\mathrm{al}^{286}$ genotyped 300 FMS patients and 270 healthy controls with regard to IL4 for specific polymorphism of the IL4 gene. They detected highly significant differences, suggesting that IL4 may be a suitable genetic marker for FMS. Investigations of various authors, however, led to inconsistent results by reporting decreased IL4 levels, ${ }^{18,287}$ no change in IL4 levels, ${ }^{288}$ or increased IL4 levels ${ }^{199}$ in FMS. In an investigation on human mast cells, even very low dosages of ambroxol inhibited anti-IgE-induced release of IL4. ${ }^{54}$

\section{Monocyte chemotactic protein I}

MCP1 (formerly called CCL2) in human monocytes acts in an anti-inflammatory fashion by inhibiting the development of proinflammatory cytokines. Not only have some investigations on fibromyalgia shown elevated levels of MCP1, ${ }^{150,274}$ but it also induced dose-dependent chronic mechanical hyperalgesia for up to 6 weeks in an animal model. ${ }^{151}$ In their interpretation of the results, the authors suggest that MCP1 induces persistent muscular hyperalgesia and thereby chronic sensitivity toward other proalgesic substances. Ang et al ${ }^{150}$ reported elevated levels of MCP1 in FMS and demonstrated significant correlations of each change with pain severity measured using the BPI. They thus presumed that MCP1 is involved in the pathogenesis of FMS. MCP1 was also elevated in 25 FMS patients with an "altered stress response" compared to healthy controls. ${ }^{274}$ There is, however, possibly a negative clinical correlation with subjective, actually perceived stress. ${ }^{19}$ The importance of this finding has been emphasized by genetic investigations, in which markedly elevated MCP1 levels were detected in an FMS subpopulation with a specific mutation. ${ }^{289}$

If MCP1 is indeed of importance in FMS, patients might benefit from treatment with ambroxol. In an animal model, inhaled ambroxol reduced MCP1..$^{51,95}$ The effect of ambroxol by inhalation at $7.5 \mathrm{mg} / \mathrm{mL}$ was comparable to $0.5 \mathrm{mg} / \mathrm{kg}$ intraperitoneal dexamethasone. Again, potent effects comparable to cortisone have been demonstrated. ${ }^{95}$ In another animal model with several control groups, ambroxol was also able significantly to reduce experimentally elevated MCP1 for 28 days. ${ }^{152}$

\section{Inflammasomes}

Recent studies identified inflammasomes, cytosolic protein complexes in macrophages and neutrophil granulocytes, as promoters of classical cytokine-mediated inflammatory processes. ${ }^{290}$ The NLRP3 inflammasome is assumed to be activated in $\mathrm{FMS}^{291,292}$ and is considered a new therapeutic target. ${ }^{293}$ Inflammasomes are obviously inhibited in their activity if reactive oxygen species ("oxygen radicals") are reduced ${ }^{290}$ and activated by mitochondrial dysfunction, ${ }^{292}$ both of which are presumed to be present in FMS. ${ }^{57}$ Since ambroxol is a strong radical scavenger ${ }^{44,60,62-65}$ and improves mitochondrial dysfunction, ${ }^{59-61}$ it should also have an impact on this newly described pathomechanism.

\section{Interleukin I3, interleukin 5, and immunomodulation}

Following secondary data analysis, Sturgill et a ${ }^{287}$ reported a remarkable reduction of IL13 in FMS patients. This interleukin is produced by $\mathrm{T}$ lymphocytes, stimulates the differentiation of B lymphocytes, and is generally considered a central mediator in allergic reactions. In cases where decreased IL13 levels have to be discussed as missing anti-inflammatory components, ambroxol would apparently exacerbate this condition: the release of IL13 is reduced by ambroxol. ${ }^{54}$ Ambroxol also reduces IL13 if administered prior to experimentally produced hyperreactivity of the airways and subsequent exposition to allergens; however, this is not the case if administered afterward. Interestingly, overall this had a beneficial and protective effect. ${ }^{285}$ This applies similarly to IL5, which has a positive chemotactic action on eosinophilic granulocytes: Sturgill et a ${ }^{287}$ also demonstrated a reduction of IL5 in FMS. Ambroxol also has an inhibiting effect concerning IL5, and if administered prior to provocation in an animal model, suppressed hyperreactivity and airway eosinophilia and reduced inflammation of subepithelial regions. ${ }^{285}$ The relationships described raise the question of whether potent inhibition of the release of IgE-dependent mediators ${ }^{294}$ and immunomodulatory cytokines from basophilic granulocytes by ambroxol, ${ }^{54}$ as well as the immunomodulatory significance of $\mathrm{Na}_{\mathrm{v}} 1.8$ sodium-channel inhibition by ambroxol, ${ }^{295}$ are important in FMS and warrant further investigation.

\section{Symptoms associated with fibromyalgia}

Patients with fibromyalgia also suffer from hypersensitive visceral organs. Symptoms of overactive bladder, ${ }^{296}$ for instance, occur more frequently in fibromyalgia patients and depend on the severity of the disease. These can be assessed using the fibromyalgia bladder index..$^{297}$ Patients with chronic interstitial cystitis or painful bladder disorders, on the other hand, show an above-average presence of fibromyalgia. ${ }^{298}$ According to investigations on rat bladders by Drewa et al, ${ }^{299}$ ambroxol is also able to suppress bladder contractions; they thus considered the compound a therapeutic option for the treatment of overactive bladder. 
In similar fashion, irritable bowel syndrome (IBS) is also associated with fibromyalgia: FMS patients suffer more often from this disease, ${ }^{300}$ and FMS is found more often in patients with IBS. ${ }^{301}$ Besides new insights concerning the potential importance of $\mathrm{Na}_{\mathrm{v}} 1.1$ for IBS, ${ }^{302}$ especially the $\mathrm{Na}_{\mathrm{v}} 1.8$ receptor, which is selectively blocked by ambroxol, is again of importance: in general, investigations with $\mathrm{Na}_{\mathrm{v}} 1.8$-free mice and $\mathrm{Na}_{\mathrm{v}} 1.8$-inhibiting compounds showed lower (also visceral) hyperexcitability or a reduction of hyperexcitability under treatment. ${ }^{68,174,178,179,303-306}$ Knockout mice without the $\mathrm{Na}_{\mathrm{v}} 1.8$ receptor not only show little visceral pain but also no referred hyperalgesia whatsoever following stimuli in the colon. ${ }^{307}$ Furthermore, $\mathrm{Na}_{\mathrm{v}} 1.8$ mutations can be associated with gastrointestinal dysfunction. ${ }^{234}$ Since in animal models particularly, colon DRG neurons exhibit $\mathrm{Na}_{\mathrm{v}} 1.8$-mediated increase in activity of the sodium channels, Hu et $\mathrm{al}^{308}$ considered this mechanism specific for chronic visceral pain and IBS. Selective $\mathrm{Na}_{\mathrm{v}} 1.8$ blockade (such as by ambroxol) is thus considered clinically beneficial for visceral pain. ${ }^{309}$

According to a review, major influence of the sympathetic rather than the parasympathetic nervous system has been deemed responsible for fibromyalgia-associated symptoms, ${ }^{310}$ again with sequelae that might be addressed with ambroxol and have already been discussed elsewhere. Another association that is clinically not quite as important, but nevertheless fits into the concept is the fact that FMS patients more frequently suffer from dry eyes, and the prevalence of FMS in patients with Sjögren's syndrome is increased by a rate of $12 \%-31 \%{ }^{311-313}$ Ambroxol leads to an increase in tear-fluid secretion $^{314}$ and can improve sicca symptoms. ${ }^{315}$

\section{Safety, dosage, and onset and duration of effect}

In vitro, the onset of $\mathrm{Na}_{\mathrm{v}} 1.8$ blockade by ambroxol starts within a few seconds, is concentration-dependent, and fully reversible. ${ }^{34}$ In paraplegic rats, hypersensitivity to static mechanical stimuli was reduced after approximately 30 minutes for approximately 3 hours. ${ }^{70}$ In earlier topical treatments, the effect reported by patients persisted for well over 6 hours. ${ }^{27,29}$ The anti-inflammatory effect should increase over time.

In most countries, ambroxol has been sold as an over-thecounter drug for decades, owing to its good safety profile, and in 2015 the European Medicines Agency reassessed the clinical benefit:risk ratio of the drug. The selective sodiumchannel blockade of the $\mathrm{Na}_{\mathrm{v}} 1.8$ channel, which is only insignificantly expressed in the heart and the CNS, is in this case clinically beneficial. After systemic administration, ambroxol was also safe: even intravenous administration of $1 \mathrm{~g}$ (in order to boost prenatal lung maturation and for the treatment of atelectasis) is well tolerated. ${ }^{316,317}$ There are individual reports of dosages of up to $3 \mathrm{~g}$ per day over 53 days $^{318-320}$ and oral administration of $1.3 \mathrm{~g}$ ambroxol per day over 33 days. ${ }^{321}$ In a recent pilot study, ambroxol was used orally at dosages of $25 \mathrm{mg} / \mathrm{kg} /$ day up to $1,300 \mathrm{mg} /$ day for Gaucher's disease and showed good safety and tolerability, ${ }^{79}$ and in an ongoing study it is being used at $1,050 \mathrm{mg} /$ day for Parkinson's disease. ${ }^{76}$ Even in an RCT with children under 1 year of age with acute respiratory distress syndrome, no adverse events were noted with ambroxol up to $40 \mathrm{mg} / \mathrm{kg} /$ day. ${ }^{322}$

With its good bioavailability of about $80 \% \%^{323}$ and plasma levels linearly correlated with oral dosage, ${ }^{69}$ dosages very likely could be used tenfold higher (or even more) than actually used (up to $120 \mathrm{mg} / \mathrm{d}$ ) for potential systemic trials for the treatment of fibromyalgia pain without risk. As many ambroxol effects apart from selective $\mathrm{Na}_{\mathrm{v}} 1.8$ sodium-channel blockade develop more intensely over a longer period, we consider treatment for more than 4-6 weeks desirable before evaluation. However, this should not be a problem, because ambroxol has already been administered clinically at $90 \mathrm{mg}$ for 3 months $^{52}$ and even at $75 \mathrm{mg}$ twice daily without any problems for 6 months $^{324}$ and also at $75 \mathrm{mg}$ twice daily for long-term treatment of 1 year. ${ }^{325}$ A clinical trial investigating the treatment of FMS with ambroxol could even use a design comparable to an ongoing study, which is designed for 52 weeks using $225-1,050 \mathrm{mg} /$ day for another indication. ${ }^{76}$

\section{Conclusion}

Overall, we think potential RCTs with FMS patients should examine the impact of ambroxol on pain, hypersensitivity, and inflammation at dosages higher then yet approved for the over-the-counter market and for at least 6 weeks. An increasing effect should be expected and possibly could be evident clinically not before two weeks of treatment. An impact on dysfunctional descending pain pathways should not be expected, so patients with a clear response to a medication for this (indicating this special origin of pain perception) might possibly report less benefit. As it is surprising that the single substance ambroxol has so many unexpected effects on FMSrelated mechanisms, the chemical properties (eg, structure and affinity) and related substances (eg, the mother substance bromhexine) could also be worth examining further.

\section{Summary}

Fibromyalgia appears to present in subgroups concerning biological pain induction with primarily inflammatory, ${ }^{12,13,264}$ neuropathic/neurodegenerative, ${ }^{153-155}$ sympathetic, ${ }^{193,194,196}$ 
oxidative,$^{24,81,97}$ or muscular factors ${ }^{84,132,134}$ and/or central sensitization. ${ }^{42,175,176}$ On the basis of this hypothesis, fibromyalgia treatment with ambroxol should be systematically investigated, since this compound is the only treatment option used thus far that has the potential to address not just individual but all of the aforementioned aspects of pain. Nevertheless, at this point, the evidence base for ambroxol is currently not strong enough for clinical recommendation.

\section{Disclosure}

In the past 3 years, KUK has worked as a consultant and/or speaker for the following companies (*offering ambroxol): Astellas, AstraZeneca, Bionorica, Berlin Chemie, ${ }^{*}$ Boehringer Ingelheim, * Betapharm, Genzyme, Grünenthal, * Hexal,* Indivior, Kyowa Kirin, Lilly, Mundipharma, ${ }^{*}$ Ratiopharm, ${ }^{*}$ and Sanofi.* MS reports no conflicts of interest in this work.

\section{References}

1. Wolfe F, Smythe HA, Yunus MB, et al. The American College of Rheumatology 1990 criteria for the classification of fibromyalgia: report of the Multicenter Criteria Committee. Arthritis Rheum. 1990;33(2):160-172.

2. Arnold LM, Clauw DJ, McCarberg BH. Improving the recognition and diagnosis of fibromyalgia. Mayo Clin Proc. 2011;86(5):457-464.

3. Häuser W, Zimmer C, Felde E, Köllner V. Was sind die Kernsymptome des Fibromyalgiesyndroms? Ergebnisse einer Umfrage der deutschen Fibromyalgie Verband. [What are the key symptoms of fibromyalgia? Results of a survey of the German Fibromyalgia Association]. Schmerz. 2008;22(2):176-183. German.

4. Wolfe F, Clauw DJ, Fitzcharles MA, et al. Fibromyalgia criteria and severity scales for clinical and epidemiological studies: a modification of the ACR preliminary diagnostic criteria for fibromyalgia. $J$ Rheumatol. 2011;38(6):1113-1122.

5. Wolfe F, Brahler E, Hinz A, Häuser W. Fibromyalgia prevalence, somatic symptom reporting, and the dimensionality of polysymptomatic distress: results from a survey of the general population. Arthritis Care Res. 2013;65(5):777-785.

6. Branco JC, Bannwarth B, Failde I, et al. Prevalence of fibromyalgia: a survey in five European countries. Semin Arthritis Rheum. 2010;39(6):448-453.

7. Ablin JN, Oren A, Cohen S, et al. Prevalence of fibromyalgia in the Israeli population: a population-based study to estimate the prevalence of fibromyalgia in the Israeli population using the London Fibromyalgia Epidemiology Study Screening Questionnaire (LFESSQ). Clin Exp Rheumatol. 2012;30(6 Suppl 74):39-43.

8. Lawrence RC, Felson DT, Helmick CG, et al. Estimates of the prevalence of arthritis and other rheumatic conditions in the United States: part II. Arthritis Rheum. 2008;58(1):26-35.

9. Torgrimson-Ojerio B, Ross RL, Dieckmann NF, et al. Preliminary evidence of a blunted anti-inflammatory response to exhaustive exercise in fibromyalgia. J Neuroimmunol. 2014;277(1-2):160-167.

10. Garcia JJ, Cidoncha A, Bote ME, Hinchado MD, Ortega E. Altered profile of chemokines in fibromyalgia patients. Ann Clin Biochem. 2014;51(Pt 5):576-581.

11. Behm FG, Gavin IM, Karpenko O, et al. Unique immunologic patterns in fibromyalgia. BMC Clin Pathol. 2012;12:25.

12. Uçeyler N, Häuser W, Sommer C. Systematic review with metaanalysis: cytokines in fibromyalgia syndrome. BMC Musculoskelet Disord. 2011;12:245.

13. Rodriguez-Pinto I, Agmon-Levin N, Howard A, Shoenfeld Y. Fibromyalgia and cytokines. Immunol Lett. 2014;161(2):200-203.
14. Hernandez ME, Becerril E, Perez M, et al. Proinflammatory cytokine levels in fibromyalgia patients are independent of body mass index. BMC Res Notes. 2010;3:156.

15. Nugraha B, Korallus C, Kielstein H, Gutenbrunner C. CD3+CD56+ natural killer $\mathrm{T}$ cells in fibromyalgia syndrome patients: association with the intensity of depression. Clin Exp Rheumatol. 2013;31(6 Supp1 79): S9-S15.

16. Menzies V, Lyon DE. Integrated review of the association of cytokines with fibromyalgia and fibromyalgia core symptoms. Biol Res Nurs. 2010;11(4):387-394.

17. Gür A, Oktayoglu P. Status of immune mediators in fibromyalgia. Curr Pain Headache Rep. 2008;12(3):175-181.

18. Uceyler N, Valenza R, Stock M, Schedel R, Sprotte G, Sommer C. Reduced levels of antiinflammatory cytokines in patients with chronic widespread pain. Arthritis Rheum. 2006;54(8):2656-2664.

19. Menzies V, Lyon DE, Elswick RK Jr, Montpetit AJ, McCain NL. Psychoneuroimmunological relationships in women with fibromyalgia. Biol Res Nurs. 2013;15(2):219-225.

20. Bradley LA. Pathophysiology of fibromyalgia. Am J Med. 2009;122(12 Suppl):S22-S30.

21. Tak LM, Cleare AJ, Ormel J, et al. Meta-analysis and meta-regression of hypothalamic-pituitary-adrenal axis activity in functional somatic disorders. Biol Psychol. 2011;87(2):183-194.

22. Toker A, Kucuksen S, Kucuk A, Cicekler H. Serum ischemia-modified albumin and malondialdehyde levels and superoxide dismutase activity in patients with fibromyalgia. Clin Lab. 2014;60(10):1609-1615.

23. Akbas A, Inanir A, Benli I, Onder Y, Aydogan L. Evaluation of some antioxidant enzyme activities (SOD and GPX) and their polymorphisms (MnSOD2 Ala9Val, GPX1 Pro198Leu) in fibromyalgia. Eur Rev Med Pharmacol Sci. 2014;18(8):1199-1203.

24. Bagis S, Tamer L, Sahin G, et al. Free radicals and antioxidants in primary fibromyalgia: an oxidative stress disorder? Rheumatol Int. 2005;25(3):188-190.

25. Martinez-Lavin M. Fibromyalgia: when distress becomes (un)sympathetic pain. Pain Res Treat. 2012;2012:981565.

26. Vargas-Alarcon G, Alvarez-Leon E, Fragoso JM, et al. A SCN9A geneencoded dorsal root ganglia sodium channel polymorphism associated with severe fibromyalgia. BMC Musculoskelet Disord. 2012;13:23.

27. Kern KU, Weiser T. [Topical ambroxol for the treatment of neuropathic pain: a first clinical observation]. Schmerz. 2015;29(6):632-640. German.

28. Kern KU, Weiser T. Topical ambroxol for the treatment of neuropathic pain: an initial clinical observation. Schmerz. 2015;29 Suppl 3:S89-S96.

29. Kern U, Weiser T. Topical ambroxol for the treatment of neuropathic or severe nociceptive pain: first case reports. Poster presented at: 9th Congress of the European Pain Federation (EFIC); September 2-5, 2015; Vienna, Austria.

30. Martinez-Martinez L, Perez L, Acosta G, et al. Ambroxol for fibromyalgia: one-group pretest-posttest open label clinical observation. Arthritis Rheumatol. 2016;68 Suppl 10:44.

31. Martinez-Martinez LA, Perez LF, Becerril-Mendoza LT, et al. Ambroxol for fibromyalgia: one group pretest-posttest open-label pilot study. Clin Rheumatol. 2017;36(8):1879-1884.

32. Beeh KM, Beier J, Esperester A, Paul LD. Antiinflammatory properties of ambroxol. Eur J Med Res. 2008;13(12):557-562.

33. Malerba M, Ragnoli B. Ambroxol in the 21st century: pharmacological and clinical update. Expert Opin Drug Metab Toxicol. 2008;4(8): 1119-1129.

34. Leffler A, Reckzeh J, Nau C. Block of sensory neuronal Na+ channels by the secreolytic ambroxol is associated with an interaction with local anesthetic binding sites. Eur J Pharmacol. 2010;630(1-3):19-28.

35. Weiser T. Nav1.8 channel blockade as an approach to the treatment of neuropathic pain. Drugs Future. 2006;31(7):597-601.

36. Weiser $\mathrm{T}$. Comparison of the effects of four $\mathrm{Na}+$ channel analgesics on TTX-resistant $\mathrm{Na}+$ currents in rat sensory neurons and recombinant Nav1.2 channels. Neurosci Lett. 2006;395(3):179-184. 
37. Akopian AN, Sivilotti L, Wood JN. A tetrodotoxin-resistant voltage-gated sodium channel expressed by sensory neurons. Nature. 1996;379(6562): 257-262.

38. Zimmermann K, Leffler A, Babes A, et al. Sensory neuron sodium channel Nav1.8 is essential for pain at low temperatures. Nature. 2007;447(7146):855-858.

39. Blair NT, Bean BP. Roles of tetrodotoxin (TTX)-sensitive Na+ current, TTX-resistant $\mathrm{Na}+$ current, and $\mathrm{Ca} 2+$ current in the action potentials of nociceptive sensory neurons. J Neurosci. 2002;22(23):10277-10290.

40. Renganathan M, Cummins TR, Waxman SG. Contribution of $\mathrm{Na}_{\mathrm{v}} 1.8$ sodium channels to action potential electrogenesis in DRG neurons. J Neurophysiol. 2001;86(2):629-640.

41. Chen WN, Lee CH, Lin SH, et al. Roles of ASIC3, TRPV1, and NaV1.8 in the transition from acute to chronic pain in a mouse model of fibromyalgia. Mol Pain. 2014;10:40.

42. Cagnie B, Coppieters I, Denecker S, Six J, Danneels L, Meeus M. Central sensitization in fibromyalgia? A systematic review on structural and functional brain MRI. Semin Arthritis Rheum. 2014;44(1):68-75.

43. Salemi S, Rethage J, Wollina U, et al. Detection of interleukin $1 \beta$ (IL-1 $\beta$ ), IL-6, and tumor necrosis factor- $\alpha$ in skin of patients with fibromyalgia. J Rheumatol. 2003;30(1):146-150.

44. Jang YY, Song JH, Shin YK, Han ES, Lee CS. Depressant effects of ambroxol and erdosteine on cytokine synthesis, granule enzyme release, and free radical production in rat alveolar macrophages activated by lipopolysaccharide. Pharmacol Toxicol. 2003;92(4):173-179.

45. Wang Y, Wang FY, Pan Z, et al. [Effects of ambroxol combined with low-dose heparin on TNF $\alpha$ and IL-1 $\beta$ in rabbits with acute lung injury]. Zhongguo Ying Yong Sheng Li Xue Za Zhi. 2011;27(2):231-235. Chinese.

46. Su X, Wang L, Song Y, Bai C. Inhibition of inflammatory responses by ambroxol, a mucolytic agent, in a murine model of acute lung injury induced by lipopolysaccharide. Intensive Care Med. 2004;30(1): 133-140.

47. Jin XZ, Zhang H. The experiment and clinical study of ambroxol against the airway inflammation of chronic hypoxic rat and patients with COPD. Eur Respir J. 2002; 20:Suppl. 38, 1658.

48. Bianchi M, Mantovani A, Erroi A, Dinarello CA, Ghezzi P. Ambroxol inhibits interleukin 1 and tumor necrosis factor production in human mononuclear cells. Agents Actions. 1990;31(3-4):275-279.

49. Pfeifer S, Zissel G, Kienast K, Müller-Quernheim J. Reduction of cytokine release of blood and bronchoalveolar mononuclear cells by ambroxol. Eur J Med Res. 1997;2(3):129-132.

50. Yang B, Yao DF, Ohuchi M, et al. Ambroxol suppresses influenza-virus proliferation in the mouse airway by increasing antiviral factor levels. Eur Respir J. 2002;19(5):952-958.

51. Zhang SJ, Jiang JX, Ren QQ, et al. Ambroxol inhalation ameliorates LPS-induced airway inflammation and mucus secretion through the extracellular signal-regulated kinase 1/2 signaling pathway. Eur $J$ Pharmacol. 2016;775:138-148.

52. Xia DH, Xi L, Xv C, et al. The protective effects of ambroxol on radiation lung injury and influence on production of transforming growth factor $\beta_{1}$ and tumor necrosis factor $\alpha$. Med Oncol. 2010;27(3):697-701.

53. Blanco I, Beritze N, Arguelles M, et al. Abnormal overexpression of mastocytes in skin biopsies of fibromyalgia patients. Clin Rheumatol. 2010;29(12):1403-1412.

54. Gibbs BF, Schmutzler W, Vollrath IB, et al. Ambroxol inhibits the release of histamine, leukotrienes and cytokines from human leukocytes and mast cells. Inflamm Res. 1999;48(2):86-93.

55. Zwadlo-Klarwasser G, Servais MD, Schmutzler W, Brosthardt P, Braam U. Ambroxol inhibits histamine release from human adenoidal mast cells. Inflamm Res. 1998;47 Suppl 1:S16-S17.

56. Gibbs BF, Wolff HH, Grabbe J. Ambroxol inhibits IgE-dependent mediator secretion from human skin mast cells. Inflamm Res. 2000;49 Suppl 1:S17-S18.

57. Sánchez-Domínguez B, Bullón P, Román-Malo L, et al. Oxidative stress, mitochondrial dysfunction and, inflammation common events in skin of patients with fibromyalgia. Mitochondrion. 2015;21:69-75.
58. Cordero MD, Moreno-Fernandez AM, Carmona-Lopez MI, et al. Mitochondrial dysfunction in skin biopsies and blood mononuclear cells from two cases of fibromyalgia patients. Clin Biochem. 2010;43(13-14):1174-1176.

59. Stetinová V, Herout V, Kvetina J. In vitro and in vivo antioxidant activity of ambroxol. Clin Exp Med. 2004;4(3):152-158.

60. Hong JS, Ko HH, Han ES, Lee CS. Inhibition of bleomycin-induced cell death in rat alveolar macrophages and human lung epithelial cells by ambroxol. Biochem Pharmacol. 2003;66(7):1297-1306.

61. Ledwozyw A, Jablonka S, Tusińska E. Wplyw ambroksolu na procesy peroksydacyjne w mitochondriach pluc psa. [The effect of ambroxol on peroxidative processes in dog lung mitochondria]. Pol Arch Weter. 1991;31(3-4):105-113. Polish.

62. Gillissen A, Bartling A, Schoen S, Schultze-Werninghaus G. Antioxidant function of ambroxol in mononuclear and polymorphonuclear cells in vitro. Lung. 1997;175(4):235-242.

63. Gaspar M, Bovaira M, Carrera-Hueso FJ, Querol M, Jimenez A, Moreno L. Efectividad de un protocolo de tratamiento topico con dimetilsulfoxido al $50 \%$ en el sindrome de dolor regional complejo tipo. [Efficacy of a topical treatment protocol with dimethyl sulfoxide $50 \%$ in type 1 complex regional pain syndrome]. Farm Hosp. 2012;36(5):385-391. Spanish.

64. Lee CS, Jang YY, Song JS, Song JH, Han ES. Ambroxol inhibits peroxynitrite-induced damage of $\alpha_{1}$-antiproteinase and free radical production in activated phagocytic cells. Pharmacol Toxicol. 2002;91(3): 140-149.

65. Ottonello L, Arduino N, Bertolotto M, Dapino P, Mancini M, Dallegri F. In vitro inhibition of human neutrophil histotoxicity by ambroxol: evidence for a multistep mechanism. Br J Pharmacol. 2003;140(4): 736-742.

66. Uçeyler N, Kewenig S, Kafke W, Kittel-Schneider S, Sommer C. Skin cytokine expression in patients with fibromyalgia syndrome is not different from controls. BMC Neurol. 2014;14:185.

67. Kosmidis ML, Koutsogeorgopoulou L, Alexopoulos H, et al. Reduction of intraepidermal nerve fiber density (IENFD) in the skin biopsies of patients with fibromyalgia: a controlled study. J Neurol Sci. 2014;347(1-2):143-147.

68. Belkouch M, Dansereau MA, Tetreault P, et al. Functional up-regulation of Nav1.8 sodium channel in $\mathrm{A} \beta$ afferent fibers subjected to chronic peripheral inflammation. J Neuroinflamm. 2014;11:45.

69. Gaida W, Klinder K, Arndt K, Weiser T. Ambroxol, a Nav1.8-preferring $\mathrm{Na}^{+}$channel blocker, effectively suppresses pain symptoms in animal models of chronic, neuropathic and inflammatory pain. Neuropharmacology. 2005;49(8):1220-1227.

70. Hama AT, Plum AW, Sagen J. Antinociceptive effect of ambroxol in rats with neuropathic spinal cord injury pain. Pharmacol Biochem Behav. 2010;97(2):249-255.

71. Moon JY, Song S, Yoon SY, et al. The differential effect of intrathecal Nav1.8 blockers on the induction and maintenance of capsaicin- and peripheral ischemia-induced mechanical allodynia and thermal hyperalgesia. Anesth Analg. 2012;114(1):215-223.

72. Bettoni L, Bonomi FG, Zani V, et al. Effects of 15 consecutive cryotherapy sessions on the clinical output of fibromyalgic patients. Clin Rheumatol. 2013;32(9):1337-1345.

73. Banfi G, Lombardi G, Colombini A, Melegati G. Whole-body cryotherapy in athletes. Sports Med. 2010;40(6):509-517.

74. McNeill A, Magalhaes J, Shen C, et al. Ambroxol improves lysosomal biochemistry in glucocerebrosidase mutation-linked Parkinson disease cells. Brain. 2014;137(Pt 5):1481-1495.

75. Ambrosi G, Ghezzi C, Zangaglia R, Levandis G, Pacchetti C, Blandini F. Ambroxol-induced rescue of defective glucocerebrosidase is associated with increased LIMP-2 and saposin C levels in GBA1 mutant Parkinson's disease cells. Neurobiol Dis. 2015;82:235-242.

76. Lawson Health Research Institute. Ambroxol as a treatment for Parkinson's disease dementia. Available from: https:/clinicaltrials.gov/ ct2/show/NCT02914366. NLM identifier: NCT02914366. Accessed July 28, 2017. 
77. Lukas J, Pockrandt AM, Seemann S, et al. Enzyme enhancers for the treatment of Fabry and Pompe disease. Mol Ther. 2015;23(3):456-464.

78. Suzuki Y. Chaperone therapy update: Fabry disease, GM1-gangliosidosis and Gaucher disease. Brain Dev. 2013;35(6):515-523.

79. Narita A, Shirai K, Itamura S, et al. Ambroxol chaperone therapy for neuronopathic Gaucher disease: a pilot study. Ann Clin Transl Neurol. 2016;3(3):200-215.

80. La Rubia M, Rus A, Molina F, Del Moral ML. Is fibromyalgia-related oxidative stress implicated in the decline of physical and mental health status? Clin Exp Rheumatol. 2013;31(6 Suppl 79):S121-S127.

81. Fatima G, Das SK, Mahdi AA. Some oxidative and antioxidative parameters and their relationship with clinical symptoms in women with fibromyalgia syndrome. Int J Rheum Dis. 2015;20(1):39-45.

82. Culić O, Cordero MD, Zanić-Grubišić T, et al. Serum activities of adenosine deaminase, dipeptidyl peptidase IV and prolyl endopeptidase in patients with fibromyalgia: diagnostic implications. Clin Rheumatol. 2016;35(10):2565-2571.

83. Cordero MD, De Miguel M, Fernandez AM, et al. Mitochondrial dysfunction and mitophagy activation in blood mononuclear cells of fibromyalgia patients: implications in the pathogenesis of the disease. Arthritis Res Ther. 2010;12(1):R17.

84. Meeus M, Nijs J, Hermans L, Goubert D, Calders P. The role of mitochondrial dysfunctions due to oxidative and nitrosative stress in the chronic pain or chronic fatigue syndromes and fibromyalgia patients: peripheral and central mechanisms as therapeutic targets? Expert Opin Ther Targets. 2013;17(9):1081-1089.

85. Cordero MD, Diaz-Parrado E, Carrion AM, et al. Is inflammation a mitochondrial dysfunction-dependent event in fibromyalgia? Antioxid Redox Signal. 2013;18(7):800-807.

86. Lazzarin A, Luerti M, Capsoni F, et al. A study of cellular immunity in newborns after prevention of respiratory distress syndrome (RDS). Int J Tissue React. 1986;8(2):157-165.

87. Aihara M, Dobashi K, Akiyama M, Naruse I, Nakazawa T, Mori M. Effects of $\mathrm{N}$-acetylcysteine and ambroxol on the production of IL-12 and IL-10 in human alveolar macrophages. Respiration. 2000;67(6):662-671.

88. Ang DC, Hilligoss J, Stump T. Mast cell stabilizer (ketotifen) in fibromyalgia: phase 1 randomized controlled clinical trial. Clin J Pain. Epub 2014 Nov 3.

89. Morrey C, Brazin J, Seyedi N, Corti F, Silver RB, Levi R. Interaction between sensory $\mathrm{C}$-fibers and cardiac mast cells in ischemia/reperfusion: activation of a local renin-angiotensin system culminating in severe arrhythmic dysfunction. J Pharmacol Exp Ther. 2010;335(1): 76-84.

90. Torresani C, Bellafiore S, De Panfilis G. Chronic urticaria is usually associated with fibromyalgia syndrome. Acta Derm Venereol. 2009;89(4):389-392.

91. Tsilioni I, Russell IJ, Stewart JM, Gleason RM, Theoharides TC. Neuropeptides CRH, SP, HK-1, and inflammatory cytokines IL-6 and TNF are increased in serum of patients with fibromyalgia syndrome, implicating mast cells. J Pharmacol Exp Ther. 2016;356(3): 664-672.

92. Zheng G, Hong S, Hayes JM, Wiley JW. Chronic stress and peripheral pain: evidence for distinct, region-specific changes in visceral and somatosensory pain regulatory pathways. Exp Neurol. 2015;273:301-311.

93. Sturgeon JA, Darnall BD, Zwickey HL, et al. Proinflammatory cytokines and DHEA-S in women with fibromyalgia: impact of psychological distress and menopausal status. J Pain Res. 2014;7:707-716.

94. Geiss A, Rohleder N, Anton F. Evidence for an association between an enhanced reactivity of interleukin-6 levels and reduced glucocorticoid sensitivity in patients with fibromyalgia. Psychoneuroendocrinology. 2012;37(5):671-684.

95. Ge LT, Liu YN, Lin XX, et al. Inhalation of ambroxol inhibits cigarette smoke-induced acute lung injury in a mouse model by inhibiting the Erk pathway. Int Immunopharmacol. 2016;33:90-98.
96. Ricciardolo FL, Sorbello V, Benedetto S, Paleari D. Effect of ambroxol and beclomethasone on lipopolysaccharide-induced nitrosative stress in bronchial epithelial cells. Respiration. 2015;89(6):572-582.

97. Fatima G, Das SK, Mahdi AA. Oxidative stress and antioxidative parameters and metal ion content in patients with fibromyalgia syndrome: implications in the pathogenesis of the disease. Clin Exp Rheumatol. 2013;31(6 Suppl 79):S128-S133.

98. Zhao SP, Guo QL, Wang RK, Wang E. [Oxidative and anti-oxidative effects of ambroxol on acute hydrochloric acid-induced lung injury in rats]. Zhong Nan Da Xue Xue Bao Yi Xue Ban. 2004;29(5):586-588. Chinese.

99. Nowak D, Antczak A, Pietras T, Bialasiewicz P, Krol M. Protective effect of ambroxol against heat- and hydrogen peroxide-induced damage to lung lipids in mice. Eur Respir J. 1994;7(9):1629-1634.

100. Ozgocmen S, Ozyurt H, Sogut S, Akyol O, Ardicoglu O, Yildizhan H. Antioxidant status, lipid peroxidation and nitric oxide in fibromyalgia: etiologic and therapeutic concerns. Rheumatol Int. 2006;26(7):598-603.

101. Jiang K, Wang X, Mao X, et al. Ambroxol alleviates hepatic ischemia reperfusion injury by antioxidant and antiapoptotic pathways. Transplant Proc. 2013;45(6):2439-2445.

102. Zhang B, Liu Y. [Prophylaxis against ventilator-induced lung injury by ambroxol]. Zhonghua Yi Xue Za Zhi. 2000;80(1):51-53. Chinese.

103. Wu X, Li S, Zhang J, et al. Meta-analysis of high doses of ambroxol treatment for acute lung injury/acute respiratory distress syndrome based on randomized controlled trials. J Clin Pharmacol. 2014;54(11):1199-1206.

104. Ma YT, Tian YP, Shi HW, Lv CH, Liu JH, Sun ZP. [Effects of high dose ambroxol on lung injury induced by paraquat in rats]. Zhonghua Lao Dong Wei Sheng Zhi Ye Bing Za Zhi. 2007;25(9):523-526. Chinese.

105. Yang F, Sun W, Yang Y, et al. SDF1-CXCR4 signaling contributes to persistent pain and hypersensitivity via regulating excitability of primary nociceptive neurons: involvement of ERK-dependent Nav1.8 up-regulation. J Neuroinflamm. 2015;12:219.

106. Schlüter F, Leffler A. Oxidation differentially modulates the recombinant voltage-gated $\mathrm{Na}^{+}$channel $\alpha$-subunits Nav1.7 and Nav1.8. Brain Res. 2016;1648(Pt A):127-135.

107. Weiser T. Presentation at the German Pain Conference 2005, October 19-22, 2005, Bremen, Germany. Schmerz 19 Suppl 1:S5-128.

108. Maes M, Mihaylova I, Kubera M, Uytterhoeven M, Vrydags N, Bosmans E. Increased plasma peroxides and serum oxidized low density lipoprotein antibodies in major depression: markers that further explain the higher incidence of neurodegeneration and coronary artery disease. $J$ Affect Disord. 2010;125(1-3):287-294.

109. Maes M, Mihaylova I, Kubera M, Uytterhoeven M, Vrydags N, Bosmans E. Increased 8-hydroxy-deoxyguanosine, a marker of oxidative damage to DNA, in major depression and myalgic encephalomyelitis/ chronic fatigue syndrome. Neuro Endocrinol Lett. 2009;30(6):715-722.

110. Wiktorska JA, Lewinski A, Stuss M, Nowak D, Pietras T, Sewerynek E. Effects of certain antioxidants on lipid peroxidation process in lung homogenates of L thyroxine-receiving rats. Neuro Endocrinol Lett. 2010;31(1):137-146.

111. Pernambuco AP, Schetino LP, Viana RS, Carvalho LS, d'Avila Reis D. The involvement of melatonin in the clinical status of patients with fibromyalgia syndrome. Clin Exp Rheumatol. 2015;33(1 Suppl 88):S14-S19.

112. Blumenthal DE, Malemud CJ. Recent strategies for drug development in fibromyalgia syndrome. Expert Rev Neurother. 2016;16(12): 1407-1411.

113. Lawson K. Potential drug therapies for the treatment of fibromyalgia. Expert Opin Investig Drugs. 2016;25(9):1071-1081.

114. Sanchez A, Calpena AC, Clares B. Evaluating the oxidative stress in inflammation: role of melatonin. Int JMol Sci.2015;16(8):16981-17004.

115. Bortolato B, Berk M, Maes M, McIntyre RS, Carvalho AF. Fibromyalgia and bipolar disorder: emerging epidemiological associations and shared pathophysiology. Curr Mol Med. 2016;16(2):119-136. 
116. Ozgocmen S, Ozyurt H, Sogut S, Akyol O. Current concepts in the pathophysiology of fibromyalgia: the potential role of oxidative stress and nitric oxide. Rheumatol Int. 2006;26(7):585-597.

117. Kim SK, Kim SH, Nah SS, et al. Association of guanosine triphosphate cyclohydrolase 1 gene polymorphisms with fibromyalgia syndrome in a Korean population. J Rheumatol. 2013;40(3):316-322.

118. Sendur OF, Turan Y, Tastaban E, Yenisey C, Serter M. Serum antioxidants and nitric oxide levels in fibromyalgia: a controlled study. Rheumatol Int. 2009;29(6):629-633.

119. Rus A, Molina F, Gasso M, Camacho MV, Peinado MA, del Moral ML. Nitric oxide, inflammation, lipid profile, and cortisol in normal- and overweight women with fibromyalgia. Biol Res Nurs. 2016;18(2):138-146.

120. Cimen OB, Cimen MY, Yapici Y, Camdeviren H. Arginase, NOS activities, and clinical features in fibromyalgia patients. Pain Med. 2009;10(5):813-818.

121. Severina IS, Bussygina OG, Pyatakova NV, Khropov YV, Krasnoperov RA. Ambroxol as an inhibitor of nitric oxide-dependent activation of soluble guanylate cyclase. Eur J Pharmacol. 2000;407(1-2):61-64.

122. Anfossi G, Russo I, Massucco P, et al. Adenosine increases human platelet levels of cGMP through nitric oxide: possible role in its antiaggregating effect. Thromb Res. 2002;105(1):71-78.

123. Kim YK, Jang YY, Han ES, Lee CS. Depressant effect of ambroxol on stimulated functional responses and cell death in rat alveolar macrophages exposed to silica in vitro. $J$ Pharmacol Exp Ther. 2002;300(2):629-637.

124. Hu F, Wang Q, Wang P, et al. 17ß-Estradiol regulates the gene expression of voltage-gated sodium channels: role of estrogen receptor $\alpha$ and estrogen receptor $\beta$. Endocrine. 2012;41(2):274-280.

125. Wang Q, Cao J, Hu F, et al. Effects of estradiol on voltage-gated sodium channels in mouse dorsal root ganglion neurons. Brain Res. 2013;1512:1-8.

126. Stening KD, Eriksson O, Henriksson KG, et al. Hormonal replacement therapy does not affect self-estimated pain or experimental pain responses in post-menopausal women suffering from fibromyalgia: a double-blind, randomized, placebo-controlled trial. Rheumatology (Oxford). 2011;50(3):544-551.

127. Dehlin M, Bjersing J, Erlandsson M, et al. Cerebrospinal Flt3 ligand correlates to tau protein levels in primary Sjögren's syndrome. Scand J Rheumatol. 2013;42(5):394-399.

128. Korszun A, Young EA, Engleberg NC, et al. Follicular phase hypothalamic-pituitary-gonadal axis function in women with fibromyalgia and chronic fatigue syndrome. J Rheumatol. 2000;27(6):1526-1530.

129. Schafranski MD, Malucelli T, Machado F, et al. Intravenous lidocaine for fibromyalgia syndrome: an open trial. Clin Rheumatol. 2009;28(7):853-855.

130. Marks DM, Newhouse A. Durability of benefit from repeated intravenous lidocaine infusions in fibromyalgia patients: a case series and literature review. Prim Care Companion CNS Disord. 2015;17(5):4088.

131. Staud R, Weyl EE, Bartley E, Price DD, Robinson ME. Analgesic and anti-hyperalgesic effects of muscle injections with lidocaine or saline in patients with fibromyalgia syndrome. Eur J Pain. 2014;18(6): 803-812.

132. Staud R, Nagel S, Robinson ME, Price DD. Enhanced central pain processing of fibromyalgia patients is maintained by muscle afferent input: a randomized, double-blind, placebo-controlled study. Pain. 2009;145(1-2):96-104.

133. Arendt-Nielsen L, Fernandez-de-Las-Penas C, Graven-Nielsen T. Basic aspects of musculoskeletal pain: from acute to chronic pain. $J$ Man Manip Ther. 2011;19(4):186-193.

134. DeSantana JM, Sluka KA. Central mechanisms in the maintenance of chronic widespread noninflammatory muscle pain. Curr Pain Headache Rep. 2008;12(5):338-343.

135. Staud R. Peripheral pain mechanisms in chronic widespread pain. Best Pract Res Clin Rheumatol. 2011;25(2):155-164.

136. Joseph EK, Levine JD. Hyperalgesic priming is restricted to isolectin B4-positive nociceptors. Neuroscience. 2010;169(1):431-435.
137. Alvarez P, Chen X, Bogen O, Green PG, Levine JD. IB4 ${ }^{+}$nociceptors mediate persistent muscle pain induced by GDNF. J Neurophysiol. 2012;108(9):2545-2553.

138. Alvarez P, Gear RW, Green PG, Levine JD. IB4-saporin attenuates acute and eliminates chronic muscle pain in the rat. Exp Neurol. 2012;233(2):859-865.

139. Sluka KA, Price MP, Breese NM, Stucky CL, Wemmie JA, Welsh MJ. Chronic hyperalgesia induced by repeated acid injections in muscle is abolished by the loss of ASIC3, but not ASIC1. Pain. 2003;106(3): 229-239.

140. Sluka KA, Kalra A, Moore SA. Unilateral intramuscular injections of acidic saline produce a bilateral, long-lasting hyperalgesia. Muscle Nerve. 2001;24(1):37-46.

141. Law LA, Sluka KA, McMullen T, Lee J, Arendt-Nielsen L, GravenNielsen T. Acidic buffer induced muscle pain evokes referred pain and mechanical hyperalgesia in humans. Pain. 2008;140(2):254-264.

142. Issberner U, Reeh PW, Steen KH. Pain due to tissue acidosis: a mechanism for inflammatory and ischemic myalgia? Neurosci Lett. 1996;208(3):191-194.

143. Birdsong WT, Fierro L, Williams FG, et al. Sensing muscle ischemia: coincident detection of acid and ATP via interplay of two ion channels. Neuron. 2010;68(4):739-749.

144. Fujii Y, Ozaki N, Taguchi T, Mizumura K, Furukawa K, Sugiura Y. TRP channels and ASICs mediate mechanical hyperalgesia in models of inflammatory muscle pain and delayed onset muscle soreness. Pain. 2008;140(2):292-304.

145. Hoheisel U, Reinöhl J, Unger T, Mense S. Acidic pH and capsaicin activate mechanosensitive group IV muscle receptors in the rat. Pain. 2004;110(1-2):149-157.

146. Yen YT, Tu PH, Chen CJ, Lin YW, Hsieh ST, Chen CC. Role of acidsensing ion channel 3 in sub-acute-phase inflammation. Mol Pain. 2009;5:1.

147. Bennett RM, Jones J, Turk DC, Russell IJ, Matallana L. An Internet survey of 2,596 people with fibromyalgia. BMC Musculoskelet Disord. 2007;8:27.

148. Häuser W, Jung E, Erbslöh-Möller B, et al. The German fibromyalgia consumer reports: a cross-sectional survey. BMC Musculoskelet Disord. 2012;13:74.

149. Christidis N, Ghafouri B, Larsson A, et al. Comparison of the levels of pro-inflammatory cytokines released in the vastus lateralis muscle of patients with fibromyalgia and healthy controls during contractions of the quadriceps muscle: a microdialysis study. PloS One. 2015;10(12):e0143856.

150. Ang DC, Moore MN, Hilligoss J, Tabbey R. MCP-1 and IL-8 as pain biomarkers in fibromyalgia: a pilot study. Pain Med. 2011;12(8): 1154-1161.

151. Alvarez P, Green PG, Levine JD. Role for monocyte chemoattractant protein-1 in the induction of chronic muscle pain in the rat. Pain. 2014;155(6):1161-1167.

152. Zhi QM, Yang LT, Sun HC. Protective effect of ambroxol against paraquat-induced pulmonary fibrosis in rats. Intern Med. 2011;50(18): 1879-1887.

153. Bazzichi L, Giacomelli C, Consensi A, et al. One year in review 2016: fibromyalgia. Clin Exp Rheumatol. 2016;34(2 Suppl 96): S145-S149.

154. Lefaucheur JP. The "paradox" of neuropathic pain associated with small-fiber lesions in the context of fibromyalgia. Pain. 2016;157(6):1364-1365.

155. Gauffin J, Hankama T, Kautiainen H, Hannonen P, Haanpää M. Neuropathic pain and use of PainDETECT in patients with fibromyalgia: a cohort study. BMC Neurol. 2013;13:21.

156. Koroschetz J, Rehm SE, Gockel U, et al. Fibromyalgia and neuropathic pain - differences and similarities: a comparison of 3057 patients with diabetic painful neuropathy and fibromyalgia. BMC Neurol. 2011;11:55.

157. Häuser W, Walitt B, Fitzcharles MA, Sommer C. Review of pharmacological therapies in fibromyalgia syndrome. Arthritis Res Ther. 2014;16(1):201. 
158. Finnerup NB, Attal N, Haroutounian S, et al. Pharmacotherapy for neuropathic pain in adults: a systematic review and meta-analysis. Lancet Neurol. 2015;14(2):162-173.

159. Uçeyler N, Sommer C. Reply: Small fibre neuropathy, fibromyalgia and dorsal root ganglia sodium channels. Brain. 2013;136(Pt 9):e247.

160. Doppler K, Rittner HL, Deckart M, Sommer C. Reduced dermal nerve fiber diameter in skin biopsies of patients with fibromyalgia. Pain. 2015;156(11):2319-2325.

161. Uçeyler N. Small fiber pathology: a culprit for many painful disorders? Pain. 2016;157 Suppl 1:S60-S66.

162. Ramirez M, Martinez-Martinez LA, Hernandez-Quintela E, Velazco-Casapia J, Vargas A, Martinez-Lavin M. Small fiber neuropathy in women with fibromyalgia: an in vivo assessment using corneal confocal bio-microscopy. Semin Arthritis Rheum. 2015;45(2): 214-219.

163. Garcia-Martin E, Garcia-Campayo J, Puebla-Guedea M, et al. Fibromyalgia is correlated with retinal nerve fiber layer thinning. PloS One. 2016;11(9):e0161574.

164. de Tommaso M, Nolano M, Iannone F, et al. Update on laser-evoked potential findings in fibromyalgia patients in light of clinical and skin biopsy features. J Neurol. 2014;261(3):461-472.

165. Kern U, Schneider S, Bialas P, et al. Topisches Ambroxol zur Therapie des CRPS: Eine neue Option?Schmerz. 2016;30 Suppl 2:S59.

166. Kinloch RA, Cox PJ. New targets for neuropathic pain therapeutics. Expert Opin Ther Targets. 2005;9(4):685-698.

167. Coggeshall RE, Tate S, Carlton SM. Differential expression of tetrodotoxin-resistant sodium channels Nav1.8 and Nav1.9 in normal and inflamed rats. Neurosci Lett. 2004;355(1-2):45-48.

168. Strickland IT, Martindale JC, Woodhams PL, Reeve AJ, Chessell IP, McQueen DS. Changes in the expression of NaV1.7, NaV1.8 and $\mathrm{NaV} 1.9$ in a distinct population of dorsal root ganglia innervating the rat knee joint in a model of chronic inflammatory joint pain. Eur $J$ Pain. 2008;12(5):564-572.

169. Faber CG, Lauria G, Merkies IS, et al. Gain-of-function Nav1.8 mutations in painful neuropathy. Proc Natl Acad Sci U S A. 2012;109(47):19444-19449.

170. Han C, Vasylyev D, Macala LJ, et al. The G1662S NaV1.8 mutation in small fibre neuropathy: impaired inactivation underlying DRG neuron hyperexcitability. J Neurol Neurosurg Psychiatry. 2014;85(5):499-505.

171. Huang J, Yang Y, Zhao P, et al. Small-fiber neuropathy Nav1.8 mutation shifts activation to hyperpolarized potentials and increases excitability of dorsal root ganglion neurons. J Neurosci. 2013;33(35): 14087-14097.

172. Huang J, Han C, Estacion M, et al. Gain-of-function mutations in sodium channel $\mathrm{Na}_{\mathrm{v}} 1.9$ in painful neuropathy. Brain. 2014;137(Pt 6): 1627-1642.

173. Brusselmans G, Nogueira H, De Schamphelaere E, Devulder J, Crombez G. Skin temperature during cold pressor test in fibromyalgia: an evaluation of the autonomic nervous system? Acta Anaesthesiol Belg. 2015;66(1):19-27.

174. Abrahamsen B, Zhao J, Asante CO, et al. The cell and molecular basis of mechanical, cold, and inflammatory pain. Science. 2008;321(5889):702-705.

175. Nielsen LA, Henriksson KG. Pathophysiological mechanisms in chronic musculoskeletal pain (fibromyalgia): the role of central and peripheral sensitization and pain disinhibition. Best Pract Res Clin Rheumatol. 2007;21(3):465-480.

176. Desmeules JA, Cedraschi C, Rapiti E, et al. Neurophysiologic evidence for a central sensitization in patients with fibromyalgia. Arthritis Rheum. 2003;48(5):1420-1429.

177. Vierck CJ, Wong F, King CD, Mauderli AP, Schmidt S, Riley JL 3rd. Characteristics of sensitization associated with chronic pain conditions. Clin J Pain. 2014;30(2):119-128.

178. Jarvis MF, Honore P, Shieh CC, et al. A-803467, a potent and selective Nav1.8 sodium channel blocker, attenuates neuropathic and inflammatory pain in the rat. Proc Natl Acad Sci USA. 2007;104(20):8520-8525.
179. Veneroni O, Maj R, Calabresi M, Faravelli L, Fariello RG, Salvati P. Anti-allodynic effect of NW-1029, a novel $\mathrm{Na}^{+}$channel blocker, in experimental animal models of inflammatory and neuropathic pain. Pain. 2003;102(1-2):17-25.

180. Littlejohn G. Neuroinflammation in fibromyalgia and CRPS: top-down or bottom-up? Nat Rev Rheumatol. 2016;12(4):242.

181. Cassisi G, Sarzi-Puttini P, Casale R, et al. Pain in fibromyalgia and related conditions. Reumatismo. 2014;66(1):72-86.

182. Sumpton JE, Moulin DE. Fibromyalgia. Handb Clin Neurol. 2014; 119:513-527.

183. Choy EH. The role of sleep in pain and fibromyalgia. Nat Rev Rheumatol. 2015;11(9):513-520.

184. Staud R. Brain imaging in fibromyalgia syndrome. Clin Exp Rheumatol. 2011;29(6 Suppl 69):S109-S117.

185. Gerhardt A, Eich W, Janke S, Leisner S, Treede RD, Tesarz J. Chronic widespread back pain is distinct from chronic local back pain: evidence from quantitative sensory testing, pain drawings, and psychometrics. Clin J Pain. 2016;32(7):568-579.

186. Blumenstiel K, Gerhardt A, Rolke R, et al. Quantitative sensory testing profiles in chronic back pain are distinct from those in fibromyalgia. Clin J Pain. 2011;27(8):682-690.

187. Wong F, Rodrigues A, Schmidt S, Vierck CJ Jr, Mauderli AP. Extreme thermal sensitivity and pain-induced sensitization in a fibromyalgia patient. Pain Res Treat. 2010;2010:912513.

188. Nagakura Y, Takahashi M, Noto T, et al. Different pathophysiology underlying animal models of fibromyalgia and neuropathic pain: comparison of reserpine-induced myalgia and chronic constriction injury rats. Behav Brain Res. 2012;226(1):242-249.

189. Renganathan M, Cummins TR, Hormuzdiar WN, Waxman SG. $\alpha$-SNS produces the slow TTX-resistant sodium current in large cutaneous afferent DRG neurons. J Neurophysiol. 2000;84(2):710-718.

190. Lai J, Gold MS, Kim CS, et al. Inhibition of neuropathic pain by decreased expression of the tetrodotoxin-resistant sodium channel, NaV1.8. Pain. 2002;95(1-2):143-152.

191. Shields SD, Ahn HS, Yang Y, et al. Nav1.8 expression is not restricted to nociceptors in mouse peripheral nervous system. Pain. 2012;153(10):2017-2030.

192. Bhardwaj HC, Arunachalam M, Kumar SL, Navis S. Neuroprotective and anti-nociceptive potential of ambroxol in oxaliplatin induced peripheral neuropathic pain in rats. Biol Med (Aligarh). 2016;8(2):1000268.

193. Okifuji A, Bradshaw DH, Olson C. Evaluating obesity in fibromyalgia: neuroendocrine biomarkers, symptoms, and functions. Clin Rheumatol. 2009;28(4):475-478.

194. Lerma C, Martinez A, Ruiz N, Vargas A, Infante O, Martinez-Lavin M. Nocturnal heart rate variability parameters as potential fibromyalgia biomarker: correlation with symptoms severity. Arthritis Res Ther. 2011;13(6):R185.

195. Martinez-Lavin M, Vidal M, Barbosa RE, Pineda C, Casanova JM, Nava A. Norepinephrine-evoked pain in fibromyalgia: randomized pilot study BMC Musculoskelet Disord. 2002;3:2.

196. Martinez-Lavin M, Solano C. Dorsal root ganglia, sodium channels, and fibromyalgia sympathetic pain. Med Hypotheses. 2009;72(1):64-66.

197. Schofield GG, Puhl HL 3rd, Ikeda SR. Properties of wild-type and fluorescent protein-tagged mouse tetrodotoxin-resistant sodium channel (NaV1.8) heterologously expressed in rat sympathetic neurons. J Neurophysiol. 2008;99(4):1917-1927.

198. Facer P, Punjabi PP, Abrari A, et al. Localisation of SCN10A gene product $\mathrm{Na}_{\mathrm{v}} 1.8$ and novel pain-related ion channels in human heart Int Heart J. 2011;52(3):146-152.

199. Kosek E, Altawil R, Kadetoff D, et al. Evidence of different mediators of central inflammation in dysfunctional and inflammatory pain: interleukin- 8 in fibromyalgia and interleukin-1 $\beta$ in rheumatoid arthritis. J Neuroimmunol. 2015;280:49-55.

200. Kadetoff D, Lampa J, Westman M, Andersson M, Kosek E. Evidence of central inflammation in fibromyalgia-increased cerebrospinal fluid interleukin-8 levels. J Neuroimmunol. 2012;242(1-2):33-38. 
201. John M, Au BT, Jose PJ, et al. Expression and release of interleukin-8 by human airway smooth muscle cells: inhibition by Th- 2 cytokines and corticosteroids. Am J Respir Cell Mol Biol. 1998;18(1):84-90.

202. Betz R. Glukokortikosteroide und Ambroxol hemmen die Sekretion entzundungsfördernder Zytokine in tracheobronchialen Epithelzellen: Mögliche Rolle des Transkriptionsfaktors NF-kappa B. [Glucocorticosteroids and ambroxol inhibit secretion of inflammatory cytokines in tracheobronchial epithelial cells: possible role of the NF- $\mathrm{\kappa B}$ transcription factor]. Pneumologie. 1997;51(5):491-492. German.

203. Li W, Mao B, Wang G, et al. [A study of the mechanism of qingre huatan therapy in treatment of acute exacerbation of chronic obstructive pulmonary disease by improving airway inflammation and mucus hypersecretion]. Zhong Xi Yi Jie He Xue Bao. 2008;6(8):799-805. Chinese.

204. Li W, Mao B, Wang G, et al. Effect of tanreqing injection on treatment of acute exacerbation of chronic obstructive pulmonary disease with Chinese medicine syndrome of retention of phlegm and heat in fei. Chin J Integr Med. 2010;16(2):131-137.

205. Yamaya M, Nishimura H, Nadine LK, Ota C, Kubo H, Nagatomi R. Ambroxol inhibits rhinovirus infection in primary cultures of human tracheal epithelial cells. Arch Pharm Res. 2014;37(4):520-529.

206. Watkins LR, Maier SF. Immune regulation of central nervous system functions: from sickness responses to pathological pain. J Intern Med. 2005;257(2):139-155.

207. Milligan ED, Watkins LR. Pathological and protective roles of glia in chronic pain. Nat Rev Neurosci. 2009;10(1):23-36.

208. Wallace DJ, Linker-Israeli M, Hallegua D, Silverman S, Silver D, Weisman MH. Cytokines play an aetiopathogenetic role in fibromyalgia: a hypothesis and pilot study. Rheumatology (Oxford). 2001;40(7):743-749.

209. Pinteaux E, Parker LC, Rothwell NJ, Luheshi GN. Expression of interleukin-1 receptors and their role in interleukin-1 actions in murine microglial cells. J Neurochem. 2002;83(4):754-763.

210. Guo W, Wang H, Watanabe M, et al. Glial-cytokine-neuronal interactions underlying the mechanisms of persistent pain. J Neurosci. 2007;27(22):6006-6018

211. McEwen BS, Kalia M. The role of corticosteroids and stress in chronic pain conditions. Metabolism. 2010;59 Suppl 1:S9-S15.

212. Staud R. Fibromyalgia pain: do we know the source? Curr Opin Rheumatol. 2004;16(2):157-163.

213. Albrecht D, Protsenko E, Mawla I, et al. Does brain glial activation have a role in fibromyalgia? A PBR28 PET study. Poster presented at: 16th World Congress on Pain; September 26-30, 2016; Yokohama, Japan.

214. Kosek E, Martinsen S, Gerdle B, et al. The translocator protein gene is associated with symptom severity and cerebral pain processing in fibromyalgia. Brain Behav Immun. 2016;58:218-227.

215. Younger J, Mackey S. Fibromyalgia symptoms are reduced by low-dose naltrexone: a pilot study. Pain Med. 2009;10(4):663-672.

216. Barkholt P, Sanchez-Guajardo V, Kirik D, Romero-Ramos M. Longterm polarization of microglia upon $\alpha$-synuclein overexpression in nonhuman primates. Neuroscience. 2012;208:85-96.

217. Su X, Maguire-Zeiss KA, Giuliano R, Prifti L, Venkatesh K, Federoff HJ. Synuclein activates microglia in a model of Parkinson's disease. Neurobiol Aging. 2008;29(11):1690-1701.

218. Hoffmann A, Ettle B, Bruno A, et al. Alpha-synuclein activates BV2 microglia dependent on its aggregation state. Biochem Biophys Res Commun. 2016;479(4):881-886.

219. Qiao H, Zhang Q, Yuan H, et al. Elevated neuronal $\alpha$-synuclein promotes microglia activation after spinal cord ischemic/reperfused injury. Neuroreport. 2015;26(11):656-661.

220. Zhang W, Wang T, Pei Z, et al. Aggregated $\alpha$-synuclein activates microglia: a process leading to disease progression in Parkinson's disease. FASEB J. 2005;19(6):533-542.

221. Klein CP, Sperotto ND, Maciel IS, Leite CE, Souza AH, Campos MM. Effects of D-series resolvins on behavioral and neurochemical changes in a fibromyalgia-like model in mice. Neuropharmacology. 2014;86:57-66.
222. Albrecht DS, MacKie PJ, Kareken DA, et al. Differential dopamine function in fibromyalgia. Brain Imaging Behav. 2016;10(3): 829-839.

223. Ledermann K, Jenewein J, Sprott H, et al. Relation of dopamine receptor 2 binding to pain perception in female fibromyalgia patients with and without depression: a $\left[{ }^{11} \mathrm{C}\right]$ raclopride PET-study. Eur Neuropsychopharmacol. 2016;26(2):320-330.

224. Migdalska-Richards A, Daly L, Bezard E, Schapira AH. Ambroxol effects in glucocerebrosidase and $\alpha$-synuclein transgenic mice. Ann Neurol. 2016;80(5):766-775.

225. Chandran V, Coppola G, Nawabi H, et al. A systems-level analysis of the peripheral nerve intrinsic axonal growth program. Neuron. 2016;89(5):956-970.

226. Migdalska-Richards A, Ko WK, Li Q, Bezard E, Schapira AH. Oral ambroxol increases brain glucocerebrosidase activity in a nonhuman primate. Synapse. 2017;71(7):21967.

227. Weiser T. Ambroxol: a CNS drug? CNS Neurosci Ther. 2008;14(1): 17-24.

228. Bromhexine [package insert]. Ingelheim am Rhein, Germany: Boehringer Ingelheim; 2012.

229. Röhnert P, Schröder UH, Ziabreva I, Tager M, Reymann KG, Striggow F. Insufficient endogenous redox buffer capacity may underlie neuronal vulnerability to cerebral ischemia and reperfusion. J Neurosci Res. 2012;90(1):193-202.

230. Bagal SK, Chapman ML, Marron BE, Prime R, Storer RI, Swain NA. Recent progress in sodium channel modulators for pain. Bioorg Med Chem Lett. 2014;24(16):3690-3699.

231. Han C, Hoeijmakers JG, Ahn HS, et al. Nav1.7-related small fiber neuropathy: impaired slow-inactivation and DRG neuron hyperexcitability. Neurology. 2012;78(21):1635-1643.

232. Hoeijmakers JG, Merkies IS, Gerrits MM, Waxman SG, Faber CG. Genetic aspects of sodium channelopathy in small fiber neuropathy. Clin Genet. 2012;82(4):351-358.

233. Faber CG, Hoeijmakers JG, Ahn HS, et al. Gain of function Nav1.7 mutations in idiopathic small fiber neuropathy. Ann Neurol. 2012;71(1):26-39.

234. Dabby R, Sadeh M, Broitman Y, Yosovich K, Dickman R, LeshinskySilver E. Painful small fiber neuropathy with gastroparesis: a new phenotype with a novel mutation in the SCN10A gene. JClin Neurosci. 2016;26:84-88.

235. Black JA, Hoeijmakers JG, Faber CG, Merkies IS, Waxman SG. NaV1.7: stress-induced changes in immunoreactivity within magnocellular neurosecretory neurons of the supraoptic nucleus. Mol Pain. 2013;9:39.

236. Brouwer BA, Merkies IS, Gerrits MM, Waxman SG, Hoeijmakers JG, Faber CG. Painful neuropathies: the emerging role of sodium channelopathies. J Peripher Nerv Syst. 2014;19(2):53-65.

237. Eberhardt MJ, Leffler A. Schmerz und Schmerzlosigkeit : Mutationen spannungsabhängiger Natriumkanäle. [Pain and analgesia: mutations of voltage-gated sodium channels]. Schmerz. 2017;31(1):14-22. German.

238. Uçeyler N, Häuser W, Sommer C. A systematic review on the effectiveness of treatment with antidepressants in fibromyalgia syndrome. Arthritis Rheum. 2008;59(9):1279-1298.

239. Dick IE, Brochu RM, Purohit Y, Kaczorowski GJ, Martin WJ, Priest BT. Sodium channel blockade may contribute to the analgesic efficacy of antidepressants. J Pain. 2007;8(4):315-324.

240. Wang SY, Calderon J, Wang GK. Block of neuronal Na+ channels by antidepressant duloxetine in a state-dependent manner. Anesthesiology. 2010;113(3):655-665.

241. Stoetzer C, Papenberg B, Doll T, et al. Differential inhibition of cardiac and neuronal $\mathrm{Na}^{+}$channels by the selective serotonin-norepinephrine reuptake inhibitors duloxetine and venlafaxine. Eur J Pharmacol. 2016;783:1-10.

242. VanderWeide LA, Smith SM, Trinkley KE. A systematic review of the efficacy of venlafaxine for the treatment of fibromyalgia. J Clin Pharm Ther. 2015;40(1):1-6. 
243. Suter MR, Kirschmann G, Laedermann CJ, Abriel H, Decosterd I. Rufinamide attenuates mechanical allodynia in a model of neuropathic pain in the mouse and stabilizes voltage-gated sodium channel inactivated state. Anesthesiology. 2013;118(1):160-172.

244. Cheng KI, Wang HC, Chang LL, et al. Pretreatment with intrathecal amitriptyline potentiates anti-hyperalgesic effects of post-injury intraperitoneal amitriptyline following spinal nerve ligation. BMC Neurol. 2012;12:44

245. Song JH, Ham SS, Shin YK, Lee CS. Amitriptyline modulation of $\mathrm{Na}^{+}$channels in rat dorsal root ganglion neurons. Eur J Pharmacol. 2000;401(3):297-305.

246. Bielefeldt K, Ozaki N, Whiteis C, Gebhart GF. Amitriptyline inhibits voltage-sensitive sodium currents in rat gastric sensory neurons. Dig Dis Sci. 2002;47(5):959-966.

247. Hur YK, Choi IS, Cho JH, et al. Effects of carbamazepine and amitriptyline on tetrodotoxin-resistant $\mathrm{Na}+$ channels in immature rat trigeminal ganglion neurons. Arch Pharm Res. 2008;31(2):178-182.

248. Patkar AA, Masand PS, Krulewicz S, et al. A randomized, controlled, trial of controlled release paroxetine in fibromyalgia. Am J Med 2007; 120(5):448-454.

249. Wiffen PJ, Derry S, Moore RA, et al. Antiepileptic drugs for neuropathic pain and fibromyalgia: an overview of Cochrane reviews Cochrane Database Syst Rev. 2013;(11):CD010567.

250. Zhang JL, Yang JP, Zhang JR, et al. Gabapentin reduces allodynia and hyperalgesia in painful diabetic neuropathy rats by decreasing expression level of Nav1.7 and p-ERK1/2 in DRG neurons. Brain Res. 2013; 1493:13-18.

251. Natkunarajah J, Atherton D, Elmslie F, Mansour S, Mortimer P. Treatment with carbamazepine and gabapentin of a patient with primary erythermalgia (erythromelalgia) identified to have a mutation in the SCN9A gene, encoding a voltage-gated sodium channel. Clin Exp Dermatol. 2009;34(8):e640-e642.

252. Devigili G, Eleopra R, Pierro T, et al. Paroxysmal itch caused by gainof-function Nav1.7 mutation. Pain. 2014;155(9):1702-1707.

253. Bi RY, Ding Y, Gan YH. Non-steroidal anti-inflammatory drugs attenuate hyperalgesia and block upregulation of trigeminal ganglionic sodium channel 1.7 after induction of temporomandibular joint inflammation in rats. Chin J Dent Res. 2016;19(1):35-42.

254. Huang ZJ, Hsu E, Li HC, Rosner AL, Rupert RL, Song XJ. Topical application of compound Ibuprofen suppresses pain by inhibiting sensory neuron hyperexcitability and neuroinflammation in a rat model of intervertebral foramen inflammation. J Pain. 2011;12(1): $141-152$.

255. Gould HJ 3rd, England JD, Soignier RD, et al. Ibuprofen blocks changes in $\mathrm{Na}_{\mathrm{v}} 1.7$ and 1.8 sodium channels associated with complete Freund's adjuvant-induced inflammation in rat. J Pain. 2004;5(5):270-280.

256. Leffler A, Frank G, Kistner K, et al. Local anesthetic-like inhibition of voltage-gated $\mathrm{Na}^{+}$channels by the partial $\mu$-opioid receptor agonist buprenorphine. Anesthesiology. 2012;116(6):1335-1346.

257. Haeseler G, Foadi N, Ahrens J, Dengler R, Hecker H, Leuwer M. Tramadol, fentanyl and sufentanil but not morphine block voltageoperated sodium channels. Pain. 2006;126(1-3):234-244.

258. Weibel R, Reiss D, Karchewski L, et al. Mu opioid receptors on primary afferent nav1.8 neurons contribute to opiate-induced analgesia: insight from conditional knockout mice. PloS One. 2013;8(9):e74706.

259. Reckzeh J. Die Wirkung des Sekretolytikums Ambroxol an neuronalen Natriumkanälen durch die Interaktion mit der Lokalanästhetikumbindungsstelle [PhD thesis]. Erlangen: Friedrich-Alexander-Universität Erlangen-Nürnberg; 2010.

260. de Mey C, Koelsch S, Richter E, Pohlmann T, Sousa R. Efficacy and safety of ambroxol lozenges in the treatment of acute uncomplicated sore throat: a pooled analysis. Drug Res (Stuttg). 2016;66(7):384-392.

261. Chenot JF, Weber P, Friede T. Efficacy of ambroxol lozenges for pharyngitis: a meta-analysis. BMC Fam Pract. 2014;15:45.

262. Weiser T, Kinder K, Arndt K, Gaida W. Ambroxol unterdrückt hocheffektiv Symptome des chronischen, neuropathischen und inflammatorischen Schmerzes. Schmerz. 2007;21 Suppl 1:97.
263. Uçeyler N, Sommer C. Cytokine regulation in animal models of neuropathic pain and in human diseases. Neurosci Lett. 2008;437(3):194-198.

264. Staud R. Cytokine and immune system abnormalities in fibromyalgia and other central sensitivity syndromes. Curr Rheumatol Rev. 2015;11(2):109-115

265. Boettger MK, Weber K, Grossmann D, et al. Spinal tumor necrosis factor $\alpha$ neutralization reduces peripheral inflammation and hyperalgesia and suppresses autonomic responses in experimental arthritis: a role for spinal tumor necrosis factor $\alpha$ during induction and maintenance of peripheral inflammation. Arthritis Rheum. 2010;62(5):1308-1318.

266. DeLeo JA, Colburn RW, Nichols M, Malhotra A. Interleukin6-mediated hyperalgesia/allodynia and increased spinal IL-6 expression in a rat mononeuropathy model. J Interferon Cytokine Res. 1996;16(9):695-700.

267. Xu XJ, Hao JX, Andell-Jonsson S, Poli V, Bartfai T, WiesenfeldHallin Z. Nociceptive responses in interleukin-6-deficient mice to peripheral inflammation and peripheral nerve section. Cytokine. 1997;9(12):1028-1033.

268. Sommer C, Schmidt C, George A. Hyperalgesia in experimental neuropathy is dependent on the TNF receptor 1. Exp Neurol. 1998;151(1): 138-142.

269. Savino W, Mendes-da-Cruz DA, Lepletier A, Dardenne M. Hormonal control of T-cell development in health and disease. Nat Rev Endocrinol. 2016;12(2):77-89.

270. Malek H, Ebadzadeh MM, Safabakhsh R, Razavi A, Zaringhalam J. Dynamics of the HPA axis and inflammatory cytokines: insights from mathematical modeling. Comput Biol Med. 2015;67:1-12.

271. Gupta D, Morley JE. Hypothalamic-pituitary-adrenal (HPA) axis and aging. Compr Physiol. 2014;4(4):1495-1510.

272. Ortega E, Bote ME, Giraldo E, Garcia JJ. Aquatic exercise improves the monocyte pro- and anti-inflammatory cytokine production balance in fibromyalgia patients. Scand J Med Sci Sports. 2012;22(1):104-112.

273. Bote ME, Garcia JJ, Hinchado MD, Ortega E. Fibromyalgia: antiinflammatory and stress responses after acute moderate exercise. PloS One. 2013;8(9):e74524.

274. Bote ME, Garcia JJ, Hinchado MD, Ortega E. Inflammatory/stress feedback dysregulation in women with fibromyalgia. Neuroimmunomodulation. 2012;19(6):343-351.

275. Wang H, Buchner M, Moser MT, Daniel V, Schiltenwolf M. The role of IL-8 in patients with fibromyalgia: a prospective longitudinal study of 6 months. Clin J Pain. 2009;25(1):1-4.

276. Mendieta D, de la Cruz-Aguilera DL, Barrera-Villalpando MI, et al. IL-8 and IL-6 primarily mediate the inflammatory response in fibromyalgia patients. J Neuroimmunol. 2016;290:22-25.

277. Xiao Y, Haynes WL, Michalek JE, Russell IJ. Elevated serum highsensitivity C-reactive protein levels in fibromyalgia syndrome patients correlate with body mass index, interleukin-6, interleukin-8, erythrocyte sedimentation rate. Rheumatol Int. 2013;33(5):1259-1264.

278. Ranzolin A, Duarte AL, Bredemeier M, et al. Evaluation of cytokines, oxidative stress markers and brain-derived neurotrophic factor in patients with fibromyalgia: a controlled cross-sectional study. Cytokine. 2016;84:25-28.

279. Watkins LR, Wiertelak EP, Goehler LE, Smith KP, Martin D, Maier SF. Characterization of cytokine-induced hyperalgesia. Brain Res. 1994;654(1):15-26.

280. Schaible HG. Nociceptive neurons detect cytokines in arthritis. Arthritis Res Ther. 2014;16(5):470.

281. Imamura M, Targino RA, Hsing WT, et al. Concentration of cytokines in patients with osteoarthritis of the knee and fibromyalgia. Clin Interv Aging. 2014;9:939-944.

282. Nakamura T, Schwander SK, Donnelly R, et al. Cytokines across the night in chronic fatigue syndrome with and without fibromyalgia. Clin Vaccine Immunol. 2010;17(4):582-587.

283. Iannuccelli C, Di Franco M, Alessandri C, et al. Pathophysiology of fibromyalgia: a comparison with the tension-type headache, a localized pain syndrome. Ann NY Acad Sci. 2010;1193:78-83. 
284. Li F, Wang W, Hu L, Li L, Yu J. Effect of ambroxol on pneumonia caused by Pseudomonas aeruginosa with biofilm formation in an endotracheal intubation rat model. Chemotherapy. 2011;57(2):173-180.

285. Takeda K, Miyahara N, Matsubara S, et al. Immunomodulatory effects of ambroxol on airway hyperresponsiveness and inflammation. Immune Netw. 2016;16(3):165-175.

286. Yigit S, Inanir A, Tekcan A, Inanir S, Tural S, Ates O. Association between fibromyalgia syndrome and polymorphism of the IL-4 gene in a Turkish population. Gene. 2013;527(1):62-64.

287. Sturgill J, McGee E, Menzies V. Unique cytokine signature in the plasma of patients with fibromyalgia. J Immunol Res. 2014;2014:938576.

288. Wang H, Moser M, Schiltenwolf M, Buchner M. Circulating cytokine levels compared to pain in patients with fibromyalgia: a prospective longitudinal study over 6 months. J Rheumatol. 2008;35(7):1366-1370.

289. Feng J, Zhang Z, Wu X, et al. Discovery of potential new gene variants and inflammatory cytokine associations with fibromyalgia syndrome by whole exome sequencing. PloS One. 2013;8(6):e65033.

290. Chen Y, Wang L, Pitzer AL, Li X, Li PL, Zhang Y. Contribution of redox-dependent activation of endothelial Nlrp3 inflammasomes to hyperglycemia-induced endothelial dysfunction. J Mol Med (Berl). 2016;94(12):1335-1347.

291. Cordero MD, Alcocer-Gomez E, Culic O, et al. NLRP3 inflammasome is activated in fibromyalgia: the effect of coenzyme $\mathrm{Q}_{10}$. Antioxid Redox Signal. 2014;20(8):1169-1180.

292. Cordero MD, Alcocer-Gomez E, Marin-Aguilar F, et al. Mutation in cytochrome $\mathrm{B}$ gene of mitochondrial DNA in a family with fibromyalgia is associated with NLRP3-inflammasome activation. J Med Genet. 2016;53(2):113--122.

293. Zhang H, Li F, Li WW, et al. The inflammasome as a target for pain therapy. Br J Anaesth. 2016;117(6):693-707.

294. Gibbs BF. Differential modulation of IgE-dependent activation of human basophils by ambroxol and related secretolytic analogues. Int J Immunopathol Pharmacol. 2009;22(4):919-927.

295. Keh SM, Facer P, Simpson KD, Sandhu G, Saleh HA, Anand P. Increased nerve fiber expression of sensory sodium channels Nav1.7, Nav1.8, and Nav1.9 in rhinitis. Laryngoscope. 2008;118(4):573-579.

296. Chung JH, Kim SA, Choi BY, et al. The association between overactive bladder and fibromyalgia syndrome: a community survey. Neurourol Urodyn. 2013;32(1):66-69.

297. Brand K, Littlejohn G, Kristjanson L, Wisniewski S, Hassard T. The fibromyalgia bladder index. Clin Rheumatol. 2007;26(12):2097-2103.

298. Nickel JC, Tripp DA, Pontari M, et al. Interstitial cystitis/painful bladder syndrome and associated medical conditions with an emphasis on irritable bowel syndrome, fibromyalgia and chronic fatigue syndrome. J Urol. 2010;184(4):1358-1363.

299. Drewa T, Młodzik-Danielewicz N, Tyrakowski T, et al. The influence of ambroxol and capsaicin on the isolated rabbit bladder wall. Acta Pol Pharm. 2005;62(5):399-403.

300. Yang TY, Chen CS, Lin CL, Lin WM, Kuo CN, Kao CH. Risk for irritable bowel syndrome in fibromyalgia patients: a national database study. Medicine (Baltimore). 2015;94(10):e616.

301. Feng B, La JH, Schwartz ES, Gebhart GF. Irritable bowel syndromemethods, mechanisms, and pathophysiology: neural and neuro-immune mechanisms of visceral hypersensitivity in irritable bowel syndrome. Am J Physiol Gastrointest Liver Physiol. 2012;302(10):G1085-G1098.

302. Osteen JD, Herzig V, Gilchrist J, et al. Selective spider toxins reveal a role for the Nav1.1 channel in mechanical pain. Nature. 2016;534(7608): 494-499.

303. Villarreal CF, Sachs D, Cunha FQ, Parada CA, Ferreira SH. The role of $\mathrm{Na}_{\mathrm{v}} 1.8$ sodium channel in the maintenance of chronic inflammatory hypernociception. Neurosci Lett. 2005;386(2):72-77.

304. Joshi SK, Mikusa JP, Hernandez G, et al. Involvement of the TTXresistant sodium channel Nav 1.8 in inflammatory and neuropathic, but not post-operative, pain states. Pain. 2006;123(1-2):75-82.

305. Ekberg J, Jayamanne A, Vaughan CW, et al. $\mu \mathrm{O}$-conotoxin MrVIB selectively blocks $\mathrm{Na}_{\mathrm{v}} 1.8$ sensory neuron specific sodium channels and chronic pain behavior without motor deficits. Proc Natl Acad Sci US A. 2006;103(45):17030-17035.
306. Hillsley K, Lin JH, Stanisz A, et al. Dissecting the role of sodium currents in visceral sensory neurons in a model of chronic hyperexcitability using Nav1.8 and Nav1.9 null mice. J Physiol. 2006;576(Pt 1):257-267.

307. Laird JM, Souslova V, Wood JN, Cervero F. Deficits in visceral pain and referred hyperalgesia in Nav1.8 (SNS/PN3)-null mice. J Neurosci. 2002;22(19):8352-8356.

308. Hu S, Xiao Y, Zhu L, et al. Neonatal maternal deprivation sensitizes voltage-gated sodium channel currents in colon-specific dorsal root ganglion neurons in rats. Am J Physiol Gastrointest Liver Physiol. 2013;304(4):G311-G321.

309. Liu M, Wood JN. The roles of sodium channels in nociception: implications for mechanisms of neuropathic pain. Pain Med. 2011;12 Suppl 3: S93-S99.

310. Martinez-Martinez LA, Mora T, Vargas A, Fuentes-Iniestra M, Martinez-Lavin M. Sympathetic nervous system dysfunction in fibromyalgia, chronic fatigue syndrome, irritable bowel syndrome, and interstitial cystitis: a review of case-control studies. J Clin Rheumatol. 2014;20(3):146-150.

311. Choi BY, Oh HJ, Lee YJ, Song YW. Prevalence and clinical impact of fibromyalgia in patients with primary Sjögren's syndrome. Clin Exp Rheumatol. 2016;34(2 Suppl 96):S9-S13.

312. Haliloglu S, Carlioglu A, Akdeniz D, Karaaslan Y, Kosar A. Fibromyalgia in patients with other rheumatic diseases: prevalence and relationship with disease activity. Rheumatol Int. 2014;34(9):1275-1280.

313. Ostuni P, Botsios C, Sfriso P, et al. Fibromyalgia in Italian patients with primary Sjögren's syndrome. Joint Bone Spine. 2002;69(1):51-57.

314. Kim D, Kim HJ, Hyon JY, Wee WR, Shin YJ. Effects of oral mucolytics on tear film and ocular surface. Cornea. 2013;32(7):933-938.

315. Ichikawa Y, Tokunaga M, Shimizu H, Moriuchi J, Takaya M, Arimori S. Clinical trial of ambroxol (Mucosolvan) in Sjögren's syndrome. Tokai J Exp Clin Med. 1988;13(3):165-169.

316. Zhang ZQ, Wu QQ, Huang XM, Lu H. Prevention of respiratory distress syndrome in preterm infants by antenatal ambroxol: a meta-analysis of randomized controlled trials. Am J Perinatol. 2013;30(7):529-536.

317. Zwissler B. Pharmakotherapie bei akutem Lungenversagen. J Anaesth Intensivbehandl. 2002;9(1):59-67.

318. Luerti M, Lazzarin A, Corbella E, Zavattini G. An alternative to steroids for prevention of respiratory distress syndrome (RDS): multicenter controlled study to compare ambroxol and betamethasone. J Perinat Med. 1987;15(3):227-238.

319. Chiara OB, Padalino P, Guadalupi P, Bigaletto I, Nespoli A. The prevention of postoperative prevention ARDS: double-blind testing about the effects of ambroxol on pulmonary gas exchange. Urgent Chirurg Comment. 1983;6(1-2):1-6.

320. Schillings GJ. Ambroxol in the treatment of ARDS in polytraumatised patients: a report. Klinikarzt. 1992;21(8):2-8.

321. Kimya Y, Küçükkömürcü S, Ozan H, Uncu G. Antenatal ambroxol usage in the prevention of infant respiratory distress syndrome: beneficial and adverse effects. Clin Exp Obstet Gynecol. 1995;22(3):204-211.

322. Baranwal AK, Murthy AS, Singhi SC. High-dose oral ambroxol for early treatment of pulmonary acute respiratory distress syndrome: an exploratory, randomized, controlled pilot trial. J Trop Pediatr. 2015;61(5):339-350.

323. Vergin H, Bishop-Freudling GB, Miczka M, Nitsche V, Strobel K, Matzkies F. Untersuchungen zur Pharmakokinetik und Bioaquivalenz unterschiedlicher Darreichungsformen von Ambroxol. [The pharmacokinetics and bioequivalence of various dosage forms of ambroxol]. Arzneimittelforschung. 1985;35(10):1591-1595. German.

324. Zimran A, Altarescu G, Elstein D. Pilot study using ambroxol as a pharmacological chaperone in type 1 Gaucher disease. Blood Cells Mol Dis. 2013;50(2):134-137.

325. Malerba M, Ponticiello A, Radaeli A, Bensi G, Grassi V. Effect of twelve-months therapy with oral ambroxol in preventing exacerbations in patients with COPD: double-blind, randomized, multicenter, placebo-controlled study (the AMETHIST trial). Pulm Pharmacol Ther. 2004;17(1):27-34. 
326. Dong C, Wang G, Li B, et al. Anti-asthmatic agents alleviate pulmonary edema by upregulating AQP1 and AQP5 expression in the lungs of mice with OVA-induced asthma. Respir Physiol Neurobiol. 2012;181(1):21-28.

327. Bazzichi L, Rossi A, Massimetti G, et al. Cytokine patterns in fibromyalgia and their correlation with clinical manifestations. Clin Exp Rheumatol. 2007;25(2):225-230.

328. Suzuki M, Teramoto S, Matsuse T, et al. Inhibitory effect of ambroxol on superoxide anion production and generation by murine lung alveolar macrophages. J Asthma. 1998;35(3):267-272.

329. Ramachandra R, McGrew SY, Baxter JC, Kiveric E, Elmslie KS. Tetrodotoxin-resistant voltage-dependent sodium channels in identified muscle afferent neurons. J Neurophysiol. 2012;108(8):2230-2241.

330. Kern NU, Weiser T. Topisches Ambroxol zur Behandlung neuropathischer Schmerzen: Eine erste klinische Beobachtung. [Topical ambroxol for the treatment of neuropathic pain: a first clinical observation]. Schmerz. 2015;29(6):632-640. German.

331. Tai H, Wang Z, Gong H, et al. Autophagy impairment with lysosomal and mitochondrial dysfunction is an important characteristic of oxidative stress-induced senescence. Autophagy. 2017;13(1):99-113.

332. Ortega E, Garcia JJ, Bote ME, et al. Exercise in fibromyalgia and related inflammatory disorders: known effects and unknown chances. Exerc Immunol Rev. 2009;15:42-65.
333. Martinez-Lavin M. Small fibre neuropathy, fibromyalgia and dorsal root ganglia sodium channels. Brain. 2013;136(Pt 9):e246.

334. Akopian AN, Souslova V, England S, et al. The tetrodotoxin-resistant sodium channel SNS has a specialized function in pain pathways. Nat Neurosci. 1999;2(6):541-548.

335. Roza C, Laird JM, Souslova V, Wood JN, Cervero F. The tetrodotoxinresistant $\mathrm{Na}+$ channel Nav1.8 is essential for the expression of spontaneous activity in damaged sensory axons of mice. $J$ Physiol. 2003;550(Pt 3):921-926.

336. Staud R. Is it all central sensitization? Role of peripheral tissue nociception in chronic musculoskeletal pain. Curr Rheumatol Rep. 2010;12(6):448-454.

337. Giraldes AL, Salomao R, Leal PD, Brunialti MK, Sakata RK. Effect of intravenous lidocaine combined with amitriptyline on pain intensity, clinical manifestations and the concentrations of IL-1, IL-6 and IL-8 in patients with fibromyalgia: a randomized double-blind study. Int $J$ Rheum Dis. 2016;19(10):946-953.

338. Vlainich R, Issy AM, Sakata RK. Effect of intravenous lidocaine associated with amitriptyline on pain relief and plasma serotonin norepinephrine, and dopamine concentrations in fibromyalgia. Clin J Pain. 2011;27(4):285-288.

\section{Journal of Pain Research}

\section{Publish your work in this journal}

The Journal of Pain Research is an international, peer reviewed, open access, online journal that welcomes laboratory and clinical findings in the fields of pain research and the prevention and management of pain. Original research, reviews, symposium reports, hypothesis formation and commentaries are all considered for publication.

\section{Dovepress}

The manuscript management system is completely online and includes a very quick and fair peer-review system, which is all easy to use. Visit http://www.dovepress.com/testimonials.php to read real quotes from published authors. 